\title{
Experimental investigation into amplitude- dependent modal properties of an eleven-span motorway bridge
}

\author{
Ge-Wei Chen \\ Department of Civil and Environmental Engineering, The University of Auckland, Auckland, \\ New Zealand
}

Sherif Beskhyroun

Department of Civil and Environmental Engineering, The University of Auckland, Auckland, New Zealand

Piotr Omenzetter (corresponding author)

The LRF Centre for Safety and Reliability Engineering, The University of Aberdeen, Aberdeen, UK

piotr.omenzetter@abdn.ac.uk 


\begin{abstract}
This paper examines experimentally the effect of forcing and response amplitude on the variability of modal parameters of a bridge. An eleven-span motorway prestressed concrete off-ramp bridge was subjected to multiple dynamic tests with varying excitation levels by using eccentric mass shakers exerting forces in the vertical and lateral direction. The frequency sweeping technique with small increment steps in the vicinity of resonant frequencies was employed to construct frequency response functions at different shaking levels from which the natural frequencies, damping ratios and mode shapes were identified for several vertical, mixed vertical-torsional and lateral modes. Softening dynamic forcedisplacement relationships were observed for all the modes, and the natural frequencies showed clear and consistent decreasing trends with increasing response amplitude. Modal damping ratios initially increased with increasing response amplitude, but later, for the modes where experimental data were available, stabilised at elevated levels. A finite element (FE) model of the bridge was also created and the experimental modal properties compared to the numerical ones. A good agreement was generally noticed for the lower modes but the higher modes had more error. The FE model was used to assess the likely levels of structural damage that would have a similar effect on the natural frequencies as the amplitude dependence. One numerical damage scenario indicated that a reduction of $20 \%$ of stiffness in the middle of the main span would cause larger frequency shifts of some modes but amplitude dependent effects will dominate in other modes. Another numerical damage scenario was a reduction by $50 \%$ of stiffness at the bottom of the highest pier, and it was shown this type of damage would result in only one third of the frequency drop caused by the amplitude effects in a single, most affected mode.
\end{abstract}

Keywords: Full scale testing; system identification, modal testing; bridge; eccentric mass shaker; amplitude dependent modal parameters; finite element model 


\section{Introduction}

Bridge structures play a central role in modern economy, and many of them continue to be in service despite aging and the associated potential for damage accumulation. Consequently, efficient monitoring of the health of these structural systems becomes increasingly important. The commonly used methods for structural evaluation of bridges include visual inspections and localized experimental methods, e.g., acoustic emission, X-ray inspection, and ultrasonic and eddy current scanning [1-3]. However, many of these methods can be costly and time consuming, and require knowledge of, and direct access to, the structural problem location. The need for alternative means to assess the structural condition has led to the development of various monitoring techniques including vibration-based structure health monitoring (VBSHM) methods [4-7]. These are based on the well-known principle that structural damage changes the mechanical properties, such as stiffness, and thereby alters the dynamics of the structure and reveals itself in the measured dynamic responses and characteristics (e.g. modal properties). Despite the intuitive premise for the VBSHM methods, one of the major hindrances in their practical applications is that dynamic characteristics of a structure will often be significantly affected by changing environmental conditions (such as temperature) [8], and will also depend on response amplitude (directly related to the external excitation levels) [9, 10], which must be taken into account in VBSHM approaches. Thus, sound understanding of the variability in dynamic properties of a bridge structure due to typical environmental and loading level variations is required for using the VBSHM techniques reliably to discern the changes caused by actual structural damage or deterioration. Abundant literature concerned with the effects of temperature on modal parameters, quantitative relationships between temperature and modal properties, and data normalization to account for environmental variability exists [11-17]. However, comprehensive explorations of the influence of excitation force level on the variability in dynamic characteristics of bridge structures are limited, because this operational variable is difficult to precisely measure. In fact, concrete structures generally behave at least weakly nonlinearly even at moderate excitation levels due to the nature of reinforced concrete stress-strain relationship. With the increase in response amplitude, structural stiffness tends to deteriorate because of the material and structural nonlinearities and this stiffness reduction can be observed as a decrease in natural frequencies. Damping, on the other hand, represents energy dissipation in a vibrating structure, and it plays a significant role in reducing structural response to a dynamic excitation near resonance. Experimental determination is currently the only reliable way of 
quantifying damping [18], since an analytical evaluation from first principles is extremely difficult, if at all possible, due to the complicated damping mechanisms. A large volume of ambient excitation data for bridge structures have been collected and analysed by many researchers. However, Ren et al. [19] pointed out that the applicability of damping ratios identified through ambient vibration testing requires further evaluation using alternative identification techniques and other dynamic tests with large vibration amplitudes. Previous tests conducted under varying magnitude of excitation often reveal that both natural frequency and damping are strongly dependent on the magnitude of response even though the structure may behave elastically [20-27]. Zhang et al [28] found that the natural frequencies of a cable-stayed bridge can exhibit up to $1 \%$ variation within a day due to different vibration intensity under varying traffic conditions. Damping ratios were also reported as sensitive to the vibration amplitude, especially when the deck vibration exceeded a certain level. Cross et al. [29] reported that the first five modal frequencies of a deck had a tendency to decrease with the increased root-mean-square values of the vertical and lateral deck accelerations based on the analysis of three years of monitoring data of the Tamar suspension bridge. Fujino et al. [30] observed that the fundamental frequency of a suspension bridge reduced as the wind speed increased but a contrary trend was observed for damping ratio. Farrar et al. [31] noted there were significant changes in the damping ratios correlated with excitation amplitude in their tests on the Alamosa Canyon bridge. Ülker-Kaustell and Karoumi [32] found the first vertical bending mode natural frequency declined linearly with the increase of the vibrational amplitude in a ballasted, single span, concrete-steel composite railway bridge by analysing the free vibration response after a freight train passage. An opposite trend for the equivalent viscous modal damping ratio was observed. Gomez et al. [33] showed that in general larger earthquake intensities resulted in reduced vibration frequencies and higher damping ratios by analysing six seismic records of a three-span curved highway bridge. Although these observations help in gaining some insights into the influence of the excitation and response level on the variability in the dynamic characteristics of bridges, a precise and quantitative understanding of the amplitude-dependent dynamic properties of bridge structures has not been achieved yet due to the relative lack of adequate response data under broadly varying force excitation levels, especially for multiple-span highway or motorway concrete bridges, many of which have been equipped with dynamic monitoring systems in recent years [34-36].

The objective and contribution of this paper is to provide further insights into the amplitude dependency of the natural frequencies and viscous modal damping ratios of bridge 
structures in a broad vibration intensity range realised via forced vibration testing experiments. An eleven-span, post-tensioned concrete motorway bridge was tested as the case study. Frequency sweeping excitation at several forcing levels applied by rotating mass shakers was utilized to excite the bridge in the vertical and lateral direction. A series of frequency response functions (FRFs) at different levels of excitation were constructed, and natural frequencies and damping ratios were identified from these FRF curves for several vertical, mixed vertical-torsional and lateral modes. Softening relationships between the amplitude of dynamic forcing and response were observed. A consistent trend of decreasing modal frequencies with increasing forcing and response level was also clear for all the identified modes. Damping, on the other hand, initially increased, but later stabilised for those modes where testing continued into large response amplitude range. Quantitative relationships between modal parameters and response amplitude were obtained from available experimental data and used to describe the amplitude-dependent behaviour of the bridge in the tested amplitude ranges. The measured modal properties at the lowest forcing level were compared with the numerical results obtained from a finite element (FE) model and an overall good agreement was achieved, although higher modal frequencies and shapes showed larger differences. The FE model was then used for simulating two damage scenarios and comparing the frequency shifts due to damage and response amplitude effects. It was found that that even significant damage may cause modal frequency variability less noticeable than that due to the response level effects. The paper is organized as follows. Firstly, the bridge and the experimental programme are described, and then the results of modal system identification and their analyses and discussions are presented. This is followed by a description of the FE model and comparison of the numerical and experimental results. Finally, the numerical simulations of damage scenarios are conducted and observations about frequency shifts due to damage versus response amplitude are discussed. A set of conclusions rounds up the paper.

\section{Description of the bridge}

The structure under investigation is the Nelson St. off-ramp bridge located on the southern fringe of the Central Business District of Auckland, New Zealand, at a confluence of three major motorways. The bridge was built in 1976 and used for a number of years thereafter. Currently, it is closed to traffic and kept as a redundant link in the motorway junction for possible emergency and regular future uses. The closure of the bridge created an excellent 
opportunity for a longer, undisturbed and comprehensive testing campaign, a part of which is the topic of this paper. Two views of the bridge appear in Fig. 1, while Fig. 2 is a sketch explaining the overall structural form and arrangement and showing major dimensions. The bridge has a horizontal as well as vertical curvature. Its total length is $272 \mathrm{~m}$ and it comprises 11 post-tensioned concrete spans. The main span is $40 \mathrm{~m}$ long and the remaining spans vary in length between 18 and $26 \mathrm{~m}$, with the majority of them $24 \mathrm{~m}$ long. The superstructure was built of a total of 137 precast single-cell box girder segments delivered to the site, placed in their final position on movable scaffolding and then post-tensioned. Two different precast cross-sections of heights $1.73 \mathrm{~m}$ and $1.09 \mathrm{~m}$, respectively, were used and are shown in Fig. 3. The cantilevered extremities of the girder upper flange were precast separately and connected to the box section using reinforcement bars protruding from the box section. Steel guardrails were bolted to the cantilever slab of the girder on both sides along the whole length of the bridge, while a concrete channel was installed along one side of the girder cantilever slab for rainwater drainage. A $40 \mathrm{~mm}$ thick layer of mixed asphalt and crushed stone gravel or sand was used for the bridge roadway paving.

Ten solid octagonal piers of height between 4.27 and $14.43 \mathrm{~m}$ and the maximum width and thickness of $2.85 \mathrm{~m}$ and $1.42 \mathrm{~m}$, respectively, provide intermediate supports (refer to Fig. 2 for pier numbers). The North and South end of the bridge are supported by a pilebent type abutment and a gravity abutment, referred to as Abutment 1 and Abutment 2, respectively. Abutment 1 and Piers 1-3 are founded on piles whereas the remaining piers and Abutment 2 on footing type foundations.

A pair of elastomeric bearings, separated by a distance of $1.93 \mathrm{~m}$ centre-to-centre, was installed at the top of each pier and abutment to support the superstructure. At Abutment 1, sliding type bearings, with sliding direction at an angle of $20.6^{\circ}$ to the bridge longitudinal axis, were used. Shear keys were also installed at the top of Piers 2-10 to meet aseismic requirements by providing additional resistance for the superstructure should it undergo large lateral motion.

There is a hinge in the girder located between Piers 4 and 5 at a distance of $9 \mathrm{~m}$ from Pier 4. The hinge is shown in Fig. 4. It consists of two steel cantilevered I-sections protruding from the girder segment on the one side of the hinge with a fixed pot bearing at the tip of each cantilever. The girder segment on the other side of the hinge rests on the bearings. The depth of the box section segments between Pier 4 and the hinge gradually varies between $1.73 \mathrm{~m}$ to $1.09 \mathrm{~m}$. 


\section{Equipment and experimental programme}

This paper is focused on frequency sweep forced-vibration tests using rotating mass shakers conduced on the bridge as a part of a wider experimental programme, whose remaining components will be reported on other occasions. The frequency sweep forcedvibration method, when suitably large exciters are employed, can determine high quality dynamic characteristics of structures due to its capability of inducing strong responses in a wide frequency range $[37,38]$. In the present study, two large capacity eccentric mass shakers (ANCO Model MK-140-10-50) were anchored with several M16 bolts to the bridge deck (Fig. 5a) to perform frequency sweeps in both the vertical and lateral direction in the frequency range of up to $10 \mathrm{~Hz}$. Each shaker system consists of a dual-arm rotating adjustable eccentric mass, Danfoss VLT-5011 variable frequency drive controller, drive motor, timing belt speed reducer, and interconnecting three-phase cables [39]. The total mass of each shaker system is approximately $600 \mathrm{~kg}$. The required $440 \mathrm{~V}$ electrical power for a shaker was supplied by a $60 \mathrm{kVA}$ diesel generator located outside the bridge near Abutment 1 to avoid the effect of the generator on bridge vibrating responses. According to the manufacturer's specifications, each mechanical vibrator has the maximum unidirectional frequency and force capacities of $30 \mathrm{~Hz}$ and $92 \mathrm{kN}$, respectively. The amplitude and frequency of the applied force is controlled by varying the rotational speed, and the magnitude and eccentricity of the attached masses. The force output generated by each shaker, $P$, can be expressed as:

$$
P(t)=4 \pi^{2} f^{2} M R \sin 2 \pi f t
$$

where $M R$ is the shaker mass-eccentricity $(\mathrm{kg}-\mathrm{m}), f$ is the frequency of rotation $(\mathrm{Hz})$, and $t$ is time (sec). By adjusting the number of the steel masses attached to the flywheels (Fig. 5b), unidirectional harmonic excitations with low, moderate and high amplitude can be generated.

A total of 62 battery powered tri-axial Micro-Electro-Mechanical Systems (MEMS) accelerometers with an internal temperature gauge and data recording to a micro SD card (Data Concepts models X6-1A and X6-2) (Fig. 6) were used to capture the vibrational response. Before installation on a structure, the real time clock of each accelerometer is synchronized to a computer clock via a USB connection which is later also used for data download. These sensors offer a cost effective alternative to the traditional wired systems on the one hand and wireless platforms on the other. They provide sufficient data quality and reliability while avoiding time consuming and expensive cabling for the wired systems and vagaries of wireless systems such as the not infrequent data loss [40-42]. The 
accelerometer/D-cell battery units were wrapped tightly onto small plywood blocks and attached to the bridge deck by using a silicone adhesive (Fig. 6). During testing, a 12-bit resolution was used, with resulting $1 \mathrm{mg}$ resolution in the $\pm 2 \mathrm{~g}$ range, and the sampling rate was set at $80 \mathrm{~Hz}$.

Both shakers were positioned on the longest span between Piers 2 and 3 at the location selected based on a preliminary FE modal analysis to avoid nodal points of the expected modes to be excited. The laterally configured shaker was positioned at the mid-span and at the centreline of the bridge deck and the vertical shaker at $1 / 3$ of the span length and $2.5 \mathrm{~m}$ off the centreline to provide also torsional forcing (Fig. 7). Figure 7 also explains the general principles of accelerometer setup, taking the longest span as an example. During vertical sweeping tests, the 62 accelerometers were arranged along both curbs of the bridge deck generally at 1/4,1/2 and 3/4 of span-length (with the exception of two short spans at the North end that were only measured in the middle) and at the hinge location. During lateral sweeping tests, the accelerometers on the bridge deck were placed along the centreline of the bridge generally at 1/4,1/2 and 3/4 of span-length (with the exception of two longest spans between Piers 2 and 4 that were additionally measured at 1/8,3/8, 5/8 and 7/8 of their span length) and at the pier, abutment and hinge locations. Due to the availability of a large number of sensors, a single setup for each type of test sufficed to map the whole mode shapes.

Taking advantage of the ability to control the excitation force, a testing program was designed to investigate the amplitude dependent modal properties of the bridge. To that end, several detailed frequency sweeps with varying forcing mass-eccentricity were conducted in the vicinity of the identified natural frequencies. To obtain initial estimates of the resonant frequencies each shaker was configured with one small mass $(3.6 \mathrm{~kg})$ and the rotation frequency was gradually increased from 0.0 to $10.0 \mathrm{~Hz}$ with an increment of $0.1 \mathrm{~Hz}, 20$ seconds hold time at each frequency increment, and a 5 seconds ramp-up time from one frequency value to the next. The resonant frequencies of the bridge were roughly determined by picking the peaks of the power spectral densities of the recorded data signals. Then, a series of tests with a much smaller step of $0.01 \mathrm{~Hz}$ and gradually increasing mass-eccentricity values were carried out by sweeping through narrow frequency bands centred at the previously identified resonant frequencies. At each frequency step, the excitation was held constant for approximately 60 seconds to allow the bridge response to attain the steady state condition. Because of the motor torque limit, for the vertically configured shaker the maximum number of masses that could be installed was 1 big mass $(15.5 \mathrm{~kg})$ plus $1 \mathrm{small}$ 
mass $(3.6 \mathrm{~kg})$. For the laterally configured shaker, up to 8 big masses were gradually added to each flywheel. For safety reasons (loosening of anchors and avoiding damage to the bridge), the output force of the shaker was limited to $60 \mathrm{kN}$. After the bridge experienced the highest dynamic force level, it was finally excited again by a shaker with 1 small mass to check whether the previous high force level testing had had any permanent effects on the dynamic characteristics. The testing programme for the vertical shaker is shown in Table $\mathbf{1}$ and for the lateral shaker in Table 2, respectively.

The entire testing campaign reported in this paper was completed within five days (23-27 May, 2013), during which the weather conditions were stable. This, together with the large thermal mass of concrete, is believed to largely alleviate any possible influence of variations in temperature and humidity on the dynamics. This assertion is supported by an analysis reported at the end of Section 5.

\section{Modal parameter identification}

The potential resonant frequencies within the $0.0-10.0 \mathrm{~Hz}$ frequency band of interest were identified by using the peak picking (PP) method from power spectra of responses from the quick sweeping tests with a shaker equipped with one small mass. Figure 8 displays typical quick sweeping vibration responses from the mid-span measuring stations located on the longest span (see Fig. 7) during the vertical and lateral sweeps. (Note these two types of sweeps were not conducted concurrently and are only superimposed in the figure to compare them and save space.) It can be seen in Fig. 8 how the sweeping excitation mobilizes each mode in turn. The averaged normalized power spectral density (ANPSD) plots were used to detect the resonant frequencies on site. The ANPSD is defined as [43]:

$$
\operatorname{ANPSD}\left(f_{k}\right)=\frac{1}{m} \sum_{i=1}^{m} \frac{P S D_{i}\left(f_{k}\right)}{\sum_{k=1}^{n} P S D_{i}\left(f_{k}\right)}
$$

where $f_{k}$ is the $k$-th discrete frequency $(k=1, \ldots, n), P S D_{i}$ is the auto-power spectrum of the $i$-th channel, and $m$ is the total number of measurement channels. The ANPSD makes full use of the vibrational data from all the channels and, while averaging the spectra from different channels does not have clear physical meaning, it enables quick identification of modal frequencies - an attractive alternative to examining a large number of individual spectra. Figures 9a and $\mathbf{b}$ show the ANPSDs for the vertical and lateral response data, 
respectively. From these plots, a total of six vertical, one mixed vertical-torsional and eight lateral modes were identified, indicated in the figure respectively by symbols $\mathrm{V}, \mathrm{V} / \mathrm{T}$ and $\mathrm{L}$ and the mode number. (Note that the majority of modes were identified on site immediately after testing. However, some other modes with less clearly discernible peaks in the ANPSD plots, namely V5, L4 and L5, were confirmed only after more careful examination conducted off site. Due to time limitations such detailed analyses had to be skipped on site and only the clearest modes were pursued in the subsequent detailed sweeps. It will be shown that a high degree of similarity exists between the behaviour of the identified modes, and so the exclusion of the modes less strongly excited in the preliminary tests will arguably have no consequences for the general conclusions of this research.) Table 3 lists all the modes identified from the preliminary tests. In addition to the natural frequencies, information on mode shapes is also included. This takes the form of the ratio of the maximum amplitudes in the vertical $(\mathrm{V})$, torsional $(\mathrm{T})$ and lateral $(\mathrm{L})$ direction normalized with respect to the largest of the three components, and is referred to as mode coupling ratio. Note the values in Table 3 were in fact determined from the detailed frequency sweeps using one small mass (i.e. the smallest force amplitude), except for modes V5, L4 and L5 where the preliminary sweep data was used, but are reported earlier for completeness. The vertical modal component was determined by averaging the values from two accelerometers on the opposite sides of the deck, whereas the torsional component by taking their difference and dividing by two. Because during the lateral sweeps there were no measurements at the deck edges to allow for torsional component determination, these values were extracted from a FE model of the bridge (described later) to complement the experimental information and are reported in parentheses. It can be seen from Table 3 that because the bridge is curved both vertically and horizontally, all the modes show some degree of coupling between the three components. Thus, while referring to the modes as, for example, 'vertical', it should be born in mind they are not purely vertical but rather 'vertically dominant'. One mode, designated V7/T1, showed quite different pattern on one side of the hinge (vertical dominance) compared to the other side (torsional dominance) and hence was singled out and will be referred to as the mixed vertical-torsional mode.

After the preliminary, quick testing, a series of detailed, small-step frequency sweeps at different excitation levels were performed in the vicinity of the identified frequencies to accurately quantify the amplitude-dependent dynamic behaviour (see Tables 1 and 2). Figure 10 shows an example of steady-state acceleration response from a mid-span measuring station when sweeping around the frequency of mode V1 using a shaker with one big mass. 
From Figure 10, a series of ladder-shaped steady state responses segments can be clearly observed. Around time $2000 \mathrm{sec}$, the excitation was very close to the resonant frequency. For each frequency step, an approximately 40 second long section of steady state, good quality acceleration response data was selected, and a sine wave was fitted to the experimental data using a nonlinear least square regression procedure [44]. The frequency and amplitude of response were then obtained from the fitted sine wave. The acceleration amplitudes were converted to displacement amplitudes by dividing them by $4 \pi^{2} f^{2}$. Furthermore, to account for the dependence of forcing amplitude on frequency (see Eq. 1) the displacement amplitudes were further divided by $f^{2}$. Standard FRFs in the displacement versus force format would require further division of the displacement amplitudes by $4 \pi^{2} M R$, however, this last normalization step was skipped in order to better accentuate graphically the changing response amplitudes and frequency shifts in the FRF figures, which would otherwise be too crowded for some modes. The displacement amplitudes obtained as explained above are plotted as functions of frequency in Figs. 11 and 12 for the vertical and lateral modes, respectively, using the data from the measuring station with the largest response for the corresponding mode to ensure the best signal-to-noise ratio and thus small identification errors. Note the displacement amplitudes for some modes are not shown because they were either not identified on site and therefore excluded from detailed testing as explained before (modes V5, L4 and L5), or poor quality data made reliable identification difficult (mode L3). Furthermore, for some other modes (L2, L6, L7 and L8) the testing programme had to be curtailed when strong bridge vibrations felt by the testing personnel led to concerns about inflicting damage to the bridge.

In Figs. 11 and 12, clear peak shifts to the left can be observed in the response curves, which indicate the modal frequency of each vibration mode decreases with the rise in the shaking and response amplitude. However, compared with the vertical bending modes, the shifts in the lateral bending modes are clearer, since broader ranges of excitation forces were applied. Based on these response curves, the estimates of natural frequencies were obtained by fitting interpolating cubic splines [45] through the available experimental data points and finding the frequencies corresponding to the peak response magnitude of the interpolation curves. By analysing the experimental identification results statistically, it was found that the upper bound on the standard deviation of the error of natural frequencies can be assumed to be of an order of $3 \times 10^{-3} \mathrm{~Hz}$ and for peak displacement amplitudes $5 \times 10^{-5} \mathrm{~mm}$. Damping ratios were determined by using the half-power method [18]. The simple half-power method 
was deemed appropriate as the FRFs were obtained directly from the measured steady-steady sinusoidal response data in the time domain without any potential distortions associated with transformations into the frequency domain. Mode shapes were determined based on the normalized displacement amplitudes at the identified natural frequencies for all the measurement locations on the bridge.

\section{Amplitude-dependent modal properties}

Tables 4 and 5 show (respectively for the vertical and vertical-torsional, and lateral modes) further information of the detailed experimental programme for each mode. The columns on the left show the date and time of each detailed sweep together with the ambient air temperature. These temperatures were measured at 30 mins intervals with accuracy of $\pm 0.125^{\circ} \mathrm{C}$ by $11 \mathrm{MEMS}$ accelerometers located at mid-spans and average values across all the sensors are shown. The temperature data will be discussed later to assess the effect of environmental changes on the bridge dynamics. At this point, however, the reader's attention is directed to the right hand side columns of Tables $\mathbf{4}$ and $\mathbf{5}$ that show the extracted values of forcing and response amplitudes and modal frequencies and damping ratios at different forcing and displacement levels. In order to visualise better the nonlinearity in the forcedisplacement relationships, the amplitudes of displacement are plotted versus forcing amplitudes for the vertical and vertical-torsional modes in Fig. 13 and for the lateral modes in

Fig. 14, respectively. Simple power formulas of the general form $F=A d^{B}$, where $F$ is the forcing amplitude in $\mathrm{kN}, d$ is the displacement amplitude in $\mathrm{mm}$ and $A$ and $B$ are constants, were adopted to interpolate the observed relationships and their coefficients calculated via least squares fitting; these are also displayed in Figs. 13 and 14. Note the power formulas respect the physical fact that there must be no displacement without forcing. It can be observed that for the vertical and vertical-torsional modes the trends depart from straight line even in the relatively narrow range of the forcing amplitudes applied. For lateral modes L1, L2 and L6, a clear departure from straight line can also be seen, and for modes L7 and L8, even with very limited testing points available, some departure can still be discerned. The relationships between the displacement amplitude and forcing amplitude indicate softening dynamic force-displacement characteristics of the structural system within the tested range.

The trends in modal frequencies and damping ratios with increasing response amplitude are examined in Figs. 15 - 18. For vertical and vertical-torsional modes (see Fig. 15), the natural frequencies decline practically linearly with displacement amplitude in the 
tested range that varied between $0.030 \mathrm{~mm}$ and $0.858 \mathrm{~mm}$. (While there are only three data points available for each mode to draw trend lines, the required slopes at the right hand side end suggest straight lines rather than concave curves used later for lower lateral modes). For the lower modes V1, V2, V3 and V4, the total frequency drops are small, around $0.01 \mathrm{~Hz}$ (i.e. less than 0.35\%). However, the higher modes V6 and V7/T1 exhibit larger total frequency drops in the tested response range of $0.041 \mathrm{~Hz}(0.6 \%)$ and $0.155 \mathrm{~Hz}(1.9 \%)$, respectively. These different sensitivities of modal frequencies to response amplitude are also visible in the linear formulas quantifying the dependence of frequencies on response amplitude, where the negative slopes vary between $0.02 \mathrm{~Hz} / \mathrm{mm}$ and $0.43 \mathrm{~Hz} / \mathrm{mm}$ and increase as one moves from the lower to higher modes.

For the lateral bending modes (see Fig. 16), the decrements of the natural frequency with the increasing response amplitude are more noticeable and the trends are generally nonlinear. The range of displacement amplitudes varied between $0.008 \mathrm{~mm}$ and $1.660 \mathrm{~mm}$, i.e. it was wider but still of the same order as for the vertical response range. The total decreases in frequency for modes L1, L2, L6, L7 and L8 were $0.09 \mathrm{~Hz}$ (4.8\%, or when expressed in relation to the total response amplitude change $0.06 \mathrm{~Hz} / \mathrm{mm}), 0.114 \mathrm{~Hz}(3.7 \%, 0.09 \mathrm{~Hz} / \mathrm{mm})$, $0.133 \mathrm{~Hz}(2.0 \%, 0.57 \mathrm{~Hz} / \mathrm{mm}), 0.019 \mathrm{~Hz}(0.25 \%, 0.73 \mathrm{~Hz} / \mathrm{mm})$ and $0.021 \mathrm{~Hz}(0.22 \%, 0.24$ $\mathrm{Hz} / \mathrm{mm}$ ), respectively, within the tested response range. The comparison between different modes is the most meaningful when looking at the frequency changes in relation to the response amplitude changes. For modes L1, L2, L6 and L7, these values are between 0.06 $\mathrm{Hz} / \mathrm{mm}$ and $0.73 \mathrm{~Hz} / \mathrm{mm}$ and have an increasing trend as one moves from the lower to higher modes. Also, compared to the corresponding values for the vertical and vertical-torsional modes they are between two and three times larger. However, mode L8 has a lower value of $0.24 \mathrm{~Hz} / \mathrm{mm}$, which is also approximately in the middle of the values for the vertical and vertical-torsional modes. Another obvious observation is that the frequencies of modes L1, L2 and L6 initially decrease faster but subsequently the rates of decreasing gradually become slower with the increasing response amplitude. On the other hand, the interpolating curves become closer to straight lines as one moves from mode L1 to L2 to L6, as confirmed by both visual inspection of the plots as well as the power coefficients of the frequency-displacement curves that gradually approach 1 .

The damping ratios for the vertical and vertical-torsional modes are shown in Fig. 17. All the values are within the $0.55 \%$ to $1.85 \%$ range, and there is an increasing trend for larger response amplitudes. The fundamental vertical bending mode V1 has the largest increment and the damping ratio for the response amplitude of $0.86 \mathrm{~mm}$ increased by $0.66 \%$ in absolute 
terms compared to the initial value. On the other hand, damping ratio of mode V4 remains constant. The other vertical and vertical-torsional modes have intermediate absolute increments of around $0.15 \%$. Linear trends were used to interpolate between the available limited numbers of experimental data, and these have slopes between 0 and $1.1 \% / \mathrm{mm}$, with the majority of modes having slopes of $0.2-0.5 \% / \mathrm{mm}$.

Similarly to the frequencies, there are more data points available for the damping ratios of the lower lateral modes (see Fig. 18). The rising damping levels with increasing response amplitude are obvious and the maximum increment for the lateral modes is $0.36 \%$, $1.52 \%, 0.56 \%, 0.25 \%$ and $0.15 \%$ for modes L1, L2, L6, L7 and L8, respectively. However, for modes L1 and L2, the damping ratio only rises for lower response amplitudes less than approximately $0.25 \mathrm{~mm}$, while keeping practically constant afterwards. Bilinear relationships were used to fit the available data points with the slopes of the initial parts being $1.4 \% / \mathrm{mm}$ and $3.4 \% / \mathrm{mm}$ for $\mathrm{L} 1$ and $\mathrm{L} 2$, respectively. For mode L6, the damping ratio grows continuously and linearly with the response amplitude (slope $2.6 \% / \mathrm{mm}$ ), but experimental results are only available up to approximately $0.25 \mathrm{~mm}$. While there is no direct experimental evidence, it can by hypothesised, on the one hand, that the linear trend for low amplitudes actually observed for L6 confirms the similar linear trends assumed for L1 and L2, and, on the other hand, that it can be expected that mode L6 damping ratio would also plateau for larger response amplitudes. Modes L7 and L8 were only tested at two, relatively small, values of response amplitude and linear interpolation was used. Mode L8 had an average slope of $1.7 \% / \mathrm{mm}$ but mode L7 had the largest overall slope of $9.7 \% / \mathrm{mm}$. Given that for these modes the response amplitudes were small, it can be hypothesised that the available data points are within the linear damping ratio-response amplitude range observed for the remaining lateral modes.

The question arises as to how the observed changes can be physically explained. Both material and structural nonlinearities can be involved. The decreasing stiffness, which manifest itself in the softening dynamic force-displacement relationships (Figs. 13 and 14) and falling natural frequencies (Figs. 15 and 16), can be a result of the similar well-known nonlinear force-displacement characteristic of concrete and fixed elastomeric bearings. Furthermore, at elevated response levels resistance in the hinge and sliding bearings can be gradually overcome, resulting in a 'looser' structural system. Likewise, the observed increases in damping ratios (Figs. 17 and 18) can be a result of increased energy dissipation through friction at the hinge and bearings. In the case of damping, however, after a certain level of damping is reached no further increase occurs, likely because all frictional 
mechanisms are already activated. It is important to recognize that the softening dynamic stiffness indicates in fact even larger decreases in the static stiffness. This is because the relationship between the modal displacement amplitude, $q$, modal force amplitude, $f$, modal damping ratio, $\xi$, and modal static stiffness, $k$, is [18]:

$$
\frac{q}{f}=\frac{1}{2 k \xi}
$$

As can be seen in Figs. 17 and 18 and Tables $\mathbf{4}$ and 5, the modal damping ratios never decreased and in some cases increased by as much as approximately $70 \%$, the corresponding modal static stiffness drops had to overcome with a certain margin these effects of elevated damping.

After having experienced the highest level of excitation, the bridge was again shaken using only one small mass attached to the shaker. The natural frequency and damping for each mode, and broadly the entire FRFs were found to be practically identical to those registered when the bridge was initially tested at the same level of excitation (see Tables 4 and 5 and Figs. 11 and 12 where this case is indicated as ' 1 small mass (final)'). This shows that the identified amplitude dependent nonlinearities do not relate to any irrecoverable damage to the bridge as a result of testing. The potential variability of mode shapes at different forcing levels has also been checked by calculating the Modal Assurance Criterion (MAC) [46] with respect to the lowest excitation level case, and MAC values are listed in Tables 3 and 4. A MAC value equal to 1 represents a perfect correlation (i.e. linear dependence) between two mode shapes, whereas modes which are completely orthogonal (i.e. linearly independent) have a 0 MAC value. It is found that MACs are all larger than at least 0.995 , which means the mode shapes stayed constant regardless of the level of excitation.

It is well known that ambient conditions, mostly temperature, effect structural properties and response mechanisms. It is thus necessary to assess and discuss to what extent the reported experimental dynamic properties could have been affected. It has to be recognized first that Nelson St. off-ramp bridge is a massive concrete structure with considerable thermal inertia. Thus changes in the bridge structural temperature will lag behind the changes in ambient conditions and for short lived changes in the latter (such as the diurnal temperature cycle) will have considerably smaller amplitude as observed in previous studies on similar structures $[47,48]$. The modal properties will thus not be strongly affected by only small changes in bridge structural temperature. This can be seen in our own data 
presented in Tables 4 and 5. Recall that for each mode included in the tables, the bridge was first tested using one small mass and then retested at the same forcing level several hours later and at a different ambient temperature. The smallest of the temperature changes between the two tests was for mode $\mathrm{V} 6,0.5^{\circ} \mathrm{C}$, and the largest for mode $\mathrm{L} 1,6.5^{\circ} \mathrm{C}$. The differences between modal frequencies identified at the same forcing level using one small mass but at different temperatures were in both cases equal to $0.001 \mathrm{~Hz}$. On the other hand, the largest such frequency difference was $0.004 \mathrm{~Hz}$ for mode $\mathrm{L} 8$, and corresponded to $1^{\circ} \mathrm{C}$ change in the air ambient temperature. It is noted that these frequency changes are of the order of accuracy of the identification of $0.006 \mathrm{~Hz}$ mentioned before. Further assessments of the likely effects of temperature can be made with the help of results reported in literature. A study on a cell box girder, three span, $235 \mathrm{~m}$ long concrete bridge by Fu and De Wolf [49] reports that for the period of time between 7:00 am and 5:00 pm (i.e. the same time generally as in our tests), a change of $1^{\circ} \mathrm{C}$ in the ambient air temperature resulted in only $0.06^{\circ} \mathrm{C}$ change in bridge structural temperature. Further, Liu and De Wolf [47] estimated from long-term bridge monitoring results that modal frequencies did not change more than $0.8 \%$ per $1{ }^{\circ} \mathrm{C}$ change in structural temperature. Taking the most extreme ambient air temperature variation observed in our testing, i.e. $6.5^{\circ} \mathrm{C}$ for mode L1, and the above estimates from [47] and [49], suggests the maximum change in the frequency of mode L1 caused by temperature variation to be approximately $0.006 \mathrm{~Hz}$. This value is of an order smaller than the difference of $0.09 \mathrm{~Hz}$ measured at the two corresponding forcing levels (see Table 5) and of the same order as the accuracy of frequency identification. Overall, it can thus be concluded that temperature changes had only very small effects on the reported results and frequency shifts can be confidently attributed to the differences in response amplitudes.

\section{Comparison of experimental and numerical modal parameters}

One of the main benefits of field vibration testing can be validation of numerical models to be used for structural performance and condition evaluation. On the other hand, correlating the experimental results with the eigenvalue/eigenvector pairs calculated from a mathematical model helps in the interpretation of, and increases the confidence in, the modal properties identified from tests. Thus, physical testing and numerical modelling should go hand in hand whenever practical and inform each other. This section discusses the development of a threedimensional (3D) linear elastic FE model of the Nelson St. off-ramp bridge and comparison of the natural frequencies and mode shapes identified experimentally at the lowest excitation 
level (shaker with one small mass) with their counterparts derived from the FE model. (Note, precise model tuning, or updating, is not an objective of the study reported herein and will be a subject of future investigations; only manual adjustments of the FE model were deemed sufficient for the current study.)

The FE model is constructed using the ANSYS FE code [50] adopting the geometry and structural and material properties indicated in the bridge design documentation and confirmed visually on site. The main structural components, such as the box girder and hexagonal piers, are modelled using 2-node 3D elastic beam elements (Beam188). The values of material parameters used for the main components of the FE model are as follows: Young's modulus of girder concrete is $35 \mathrm{GPa}$ and for the piers and cantilever girder extremities it is $30 \mathrm{GPa}$, density of girder concrete is $2,550 \mathrm{~kg} / \mathrm{m}^{3}$ and for the piers and cantilever girder extremities it is $2,450 \mathrm{~kg} / \mathrm{m}^{3}$. The stiffness of non-structural members, such as steel rails, asphalt layer and concrete rainwater channel, are ignored but their masses are accounted for as $208 \mathrm{~kg}$ per $1 \mathrm{~m}$ length of the bridge in the longitudinal direction and modelled by point mass elements (Mass21) including the corresponding rotary inertia along the longitudinal axis of the deck.

Appropriate modelling of boundary and connectivity conditions always plays a significant role in accurately representing the actual structural dynamic behaviour. The hinge in the girder was modelled as an ideal one, i.e. with no rotational stiffness. This was based on trying a range of rotational springs and observing the resulting frequencies and mode shapes. The lateral and longitudinal stiffness of a single bearing of the type used at the pier was assumed to be $0.2 \mathrm{GN} / \mathrm{m}$, rotations associated with vertical bending were assumed free, and vertical displacements as well as torsion fully restrained. At Abutment 1, the sliding type bearings were additionally assumed to provide no translational restraint in the direction of sliding but a full perpendicular restraint. At Abutment 2, the bearings were assumed to provide full fixity, except for rotations associated with vertical bending, which were assumed free. Shear keys were assumed to remain unengaged for the relatively small motions induced by shakers. All the piers were modelled as fully fixed at the base. The bridge girder was discretized into $0.1 \mathrm{~m}$ long elements and piers into $0.2 \mathrm{~m}$ long elements. The FE model comprises 3,920 nodes and 3,488 elements (3,314 beam elements, 143 mass elements and 30 spring elements) and is shown in Fig. 19. The shifted Block-Lanczos method [51] in ANSYS was used to extract the eigenvalue/eigenvector pairs.

A comparison between the experimental and numerical modal frequencies and mode shapes (MACs) is conducted in Table 6. Additionally, for easy visualisation of the results the 
numerical frequencies are plotted against experimental frequencies Fig. 20 shows. For a perfect match between the two, all points would be located of the diagonal reference line; conversely, departures from the line indicate the degree of error. The mode shapes are displayed in Figs. 21 and 22. From Table 6 and Fig. 20, a general trend for the natural frequency and mode shape differences between the experimental and numerical results can be seen to be relatively small for the lower modes but to increase for the higher modes; this is particularly evident for the lateral modes. This demonstrates that much bigger difficulty exists in estimating higher modes from either measurements (even employing large mechanical eccentric shakers providing strong excitation) or FE predictions. The reasons include the fact that higher modes may involve more complex vibration mechanisms governed by local material and structural characteristics, nonlinearities, and larger measurement errors [52]. The vertical modes have relatively lower frequency errors, less than $2.5 \%$, compared to the vertical-torsional and lateral modes (up to $23.6 \%$ ), which indicates that the FE model captures better the mass and stiffness distribution influencing vertical vibrations. This stiffness is overwhelmingly dependent on the girder stiffness and does not pose significant challenges in modelling. However, there are larger errors for the verticaltorsional and lateral modes. Discounting the higher lateral modes L6-L8, which have noticeable errors between $10.8 \%$ and $23.6 \%$, even the lower modes still have errors up to $6.6 \%$. Modelling of the lateral displacements generally entails considering the stiffness of bearings, piers, and even foundations and soil, and is considerably more challenging and riddled with uncertainties.

The MACs of the first three vertical modes V1-V3, vertical mode V6 and lateral mode L1 are above 0.90 , which shows a reasonably good agreement. Amongst the remaining modes, V4, L2, L4-L6 still have the MAC values above 0.80, but V5, V7/T1, L3, L7 and L8 have MACs of only between 0.47 and 0.66 indicating a less satisfactory numerical modelling outcome. The varying degrees of alignment between the experimental and numerical mode shapes can also be visually confirmed in Figs. 21 and 22. Notable discrepancies include much larger experimental displacements North of the hinge for modes V2-V5, L5 and L7. However, because dynamic responses of bridge structures due to external excitation, such as earthquakes or traffic, are generally dominated by the lowest modes, the good agreement between the experimental results of the lowest few modes and their numerical counterparts shows that the FE model can be considered adequate for practical engineering applications. 


\section{Influence of amplitude dependent natural frequencies on damage detectability}

Since the amplitude dependence of modal properties has a similar qualitative influence on the modal frequencies as structural damage, i.e. both are associated with drops in frequencies, it may make detecting true damage more challenging. Both false negative and false positive damage detection errors are possible if an accurate model for the amplitude dependent effects is unavailable. It is thus of interest to explore quantitatively how the detectability of different types and extents of damage can be affected. To that end, the FE model developed in the previous section is used to simulate the following two simple damage scenarios shown schematically in Fig. 23:

- Scenario 1: A $20 \%$ reduction in the static vertical bending stiffness of a $2 \mathrm{~m}$ long girder segment in the middle of the longest span (between Piers 2 and 3); this type of numerical damage scenario could simulate cracking due to traffic overload or effect of advanced corrosion.

- Scenario 2: A 50\% reduction in the static lateral bending stiffness of $1.5 \mathrm{~m}$ long segments at the bottom of the highest Pier 3; this type of numerical damage scenario could simulate pier damage due to seismic excitation.

Table 7 shows the results of the simulations where the frequency drops caused by damage Scenarios 1 and 2 are compared to those due to the amplitude dependence of modal frequencies. Note that only the vertical and vertical-torsional modes were considered for Scenario 1 as the lateral modes were not strongly affected by the type of damage assumed in the scenario, and, for a similar reason, only lateral modes were considered for Scenario 2 . The frequency drops related to the amplitude dependency were those corresponding to the largest level of response. It is beyond the scope of this preliminary assessment to ascertain if the bridge will indeed develop the levels of vibration, when subjected to the typical excitations (such as traffic or micro tremors) it would normally be monitored under, that would cause those maximum frequency drops. Also, the influence of larger variations in temperature or humidity and other factors is ignored, as is the effect of measurement noise on system identification results.

With these limitations in mind, it can be seen that the level of damage assumed in Scenario 1 would only cause frequency shifts in modes V1 and V3 with a margin of a factor of 2 or 1.5, respectively, compared to the amplitude dependent variations, whereas it would be less than the amplitude dependent changes for modes V2, V4, V6 and V7/T1. In Scenario 
2 , only the damage related change in the frequency of mode L1 is $66 \%$ of the drop due to amplitude dependence. The other lateral modes have damage related frequency shifts significantly smaller than those due to the amplitude dependence. Thus, it can be concluded that the amplitude dependent frequency changes are, if not properly modelled, of such an order as to make even significant damage challenging to discern. However, more detailed quantitative studies are required to explore this type of challenge in damage detection.

\section{Conclusions}

The patterns of amplitude-dependent modal properties of a multi-span prestressed concrete bridge have been experimentally studied by imparting a series of vertical and lateral frequency sweep excitations at different forcing levels using large-capacity eccentric mass shakers. Frequency response functions were constructed from the acquired vibration data and several vertical, mixed vertical-torsional and lateral modes were identified. In the tested forcing and response amplitude ranges all the identified vertical, mixed vertical-torsional and lateral modes exhibit amplitude-dependent behaviour. The relationships between the dynamic forcing amplitude and response amplitude were found to have a softening character for all the identified modes. A general trend of decreasing natural frequencies with response magnitudes was also clearly identified and quantified. The rate of decrease of natural frequencies was observed to be generally higher for higher modes. Modal damping ratios were shown to increase initially with increasing response amplitudes. For several modes it was possible to continue the tests into a larger amplitude range, and then damping ratios stabilized at an elevated level. There was no clear pattern in the rate of damping ratio changes between modes.

An FE model of the bridge was created based on design specifications and drawings and on-site inspections. The model numerical frequencies and mode shapes were compared with their experimental counterparts and a good agreement was noted for the lower modes, however, more marked discrepancies occurred for the higher modes. The FE model was used in simple simulations to assess if the observed amplitude dependence of modal frequencies would pose a challenge for the application of modal based damage detection techniques. The first numerical damage scenario assumed a $20 \%$ reduction of stiffness in the middle of the main span and indicated that damage related frequency shifts of some vertical modes will be larger than those due to the amplitude effects but for other vertical modes the amplitude dependence will mask frequency drops due to damage. The second numerical damage 
scenario was a $50 \%$ reduction of stiffness at the bottom of the highest pier. This type and extent of damage caused only up to $50 \%$ of the frequency drop due to amplitude dependence in the most strongly affected first lateral mode. Thus the amplitude dependent effects can be seen to be able to influence the bridge dynamics to a similar or even larger extent as important and marked damage.

From the point of view the completeness of the experimental results, it will be useful to extend the testing programme to the several modes that were identified only later off-site and therefore not subjected to detailed frequency sweeps with varying forcing magnitude. This will help to establish a fuller picture of the phenomena studied. For a similar reason, the vertical and vertical-torsional modes could be tested beyond the rather narrow range of forcing magnitudes, however, this will depend on the capacity of exciters and safety of the structure.

Future studies should also continue several lines of inquiry which were only briefly covered in this paper to make practical use of the experimental results. Systematic updating of an FE model should be undertaken. The updating philosophy need take into account the observed trends in modal frequencies and reflect them in the model. This can help to evaluate which of the structural elements are responsible for the observed behaviour. The updated model can then be used for more realistic assessment of the bridge performance under important loading scenarios, such as traffic or earthquake.

Other sources of dynamic parameter variability, notably temperature, should be investigated. While environmental effects were not important in the presented testing programme, they may be become such for assessing long term performance of the structure exposed to a wider range of temperatures. Appropriate data should be collected via periodic or continuous monitoring of ambient and structural temperatures and its effects and a joint model for bridge dynamics under the varying loading and response levels and environmental effects established. Such a model can then be used for detailed studies on the detectability of different realistic damage scenarios where both amplitude and environmental effect can make detectability more challenging.

\section{Acknowledgements}

The authors would like to thank their supporters. New Zealand Earthquake Commission (EQC) Research Foundation provided financial support for experimental work (Grant No. UNI/578). New Zealand Transport Agency (NZTA) provided access to the bridge. Piotr 
Omenzetter's work within the LRF Centre for Safety and Reliability Engineering at the University of Aberdeen is supported by Lloyd's Register Foundation. The Foundation helps to protect life and property by supporting engineering-related education, public engagement and the application of research. Ge-Wei Chen's doctoral study is supported by China Scholarship Council (CSC) (Grant No. 2011637065).

\section{References}

[1] Alers GA. Early detection of fatigue damage by resonant ultrasonic sensors in steel components of bridges. American Society for Nondestructive Testing Fall Conference, Pittsburgh, PA 1997; 128-132.

[2] Burke SK, Rose LRF, and Scala CM. Novel approach for detecting distributed surfacebreaking cracks. Applied Physics Letters 1994; 65:, 1349-1351.

[3] Zilberstein V, and Schlicker D. MWM eddy current sensors for monitoring of crack initiation and growth during fatigue tests and in service. International Journal of Fatigue 2001; 23: 477-485.

[4] Doebling SW, Farrar CR, Prime MB, and Shevitz DW. A review of damage identification methods that examine changes in dynamic properties. Shock and Vibration Digest 1998; 30(2): 91-105.

[5] Chang PC, Flatau A, and Liu SC. Review paper: health monitoring of civil infrastructure. Structural Health Monitoring 2003; 2: 257-267.

[6] Brownjohn J. Structural health monitoring of civil infrastructure. Philosophical Transactions of the Royal Society A: Mathematical, Physical and Engineering Sciences 2007; 365(1851): 589-622.

[7] Farrar CR and Worden K. An introduction to structural health monitoring. Philosophical Transactions of the Royal Society A: Mathematical, Physical and Engineering Sciences 2007; 365(1851): 303-315.

[8] Peeters B, and De Roeck G. One-year monitoring of the Z24-Bridge: environmental effects versus damage events. Earthquake Engineering and Structural Dynamics 2001; 30(2): 149-171.

[9] Butt F, and Omenzetter P. Evaluation of seismic response trends from long term monitoring of two instrumented RC buildings including soil-structure-interaction. Advances in Civil Engineering 2012; 2012: 1-18. 
[10] Butt F, and Omenzetter P. Seismic response trends evaluation and finite element model calibration of an instrumented RC building considering soil-structure interaction and non-structural components. Engineering Structures 2014; 65: 111-123.

[11] Askegaard V, and Mossing P. Long term observation of RC-bridge using changes in natural frequencies. Nordic Concrete Research 1988; 7: 20-27.

[12] Moorty S, and Roeder CW. Temperature-dependent bridge movements. Journal of Structural Engineering, ASCE 1992; 118: 1090-1105.

[13] Cornwell P, Farrar CR, Doebling SW, and Sohn H. Environmental variability of modal properties. Experimental Techniques 1999; 23(6): 45-48.

[14] Rohrmann RG, Baessler M, Said S, Schmid W, and Ruecker WF. Structural causes of temperature affected modal data of civil structures obtained by long time monitoring. 17th International Modal Analysis Conference, Kissimmee, FL 1999; 1-6.

[15] Peeters B, Maeck J, and De Roeck G. Vibration-based damage detection in civil engineering: excitation sources and temperature effects. Smart Materials and Structures, 2001; 10(3): 518-527.

[16] Sohn H, and Farrar CR. Damage diagnosis using time series analysis of vibration signals. Smart Materials and Structures 2001; 10: 1-6.

[17] Zhao J, and De Wolf JT. Dynamic monitoring of a steel girder highway bridge. Journal of Bridge Engineering, ASCE 2002; 7(6): 350-356.

[18] Chopra AK. Dynamics of structures. Prentice Hall, Upper Saddle River, NJ 1995.

[19] Ren WX, Peng XL, and Lin YQ. Experimental and analytical studies on dynamic characteristics of a large span cable-stayed bridge. Engineering Structures 2005; 27(4): $535-548$.

[20] Udwadia FE, and Trifunac MD. Time and amplitude dependent response of structures. Earthquake Engineering and Structural Dynamics 1974; 2(4): 359-378.

[21] Leonard DR, and Eyre R. Damping and frequency measurements on eight box girder bridges. Report No. LR682, Transport and Road Research Laboratory, Department of the Environment, Crowthorne, UK 1975.

[22] Eyre R, and Tilly GP. Damping measurements on steel and composite bridges. DOE and DOT TRRL Symposium on Dynamic Behaviour of Bridges, Crowthorne, UK 1977; $22-$ 39.

[23] Minami T. Stiffness deterioration measured on a steel reinforced concrete building. Earthquake Engineering and Structural Dynamics 1987; 15(6): 697-709. 
[24] Li QS, Yang K, Wong CK, and Jeary AP. The effect of amplitude-dependent damping on wind-induced vibrations of a super tall building. Journal of Wind Engineering and Industrial Aerodynamics 2003; 91(9):1175-1198.

[25] Butterworth J, Lee JH, and Davidson B. Experimental determination of modal damping from full scale testing. 13th World Conference on Earthquake Engineering, Vancouver, BC, 2004; 1-15.

[26] Kim JY, Yu E, Kim DY, and Tamura Y. Long-term monitoring of wind-induced responses of a large-span roof structure. Journal of Wind Engineering and Industrial Aerodynamics 2011; 99: 955-963.

[27] Au SK, Zhang FL, and Ping T. Field observations on modal properties of two tall buildings under strong wind. Journal of Wind Engineering and Industrial Aerodynamics 2012; 101(4): 12-23.

[28] Zhang QW, Fan LC, and Yuan WC. Traffic-induced variability in dynamic properties of cable-stayed bridge. Earthquake Engineering and Structural Dynamics 2002; 31(11): 2015-2021.

[29] Cross EJ, Koo KY, Brownjohn JMW, and Worden K. Long-term monitoring and data analysis of the Tamar Bridge. Mechanical Systems and Signal Processing 2013; 35: 1634.

[30] Fujino Y, Abe M, Shibuya H, Yanagihara M, and Sato M. Monitoring of Hakucho suspension bridge using ambient vibration. Workshop on Research and Monitoring of Long Span Bridges, Hong Kong, 2000; 142-149.

[31] Farrar CR, Doebling SW, Cornwell PJ, and Straser EG. Variability of modal parameters measured on the Alamosa Canyon Bridge. 15th International Modal Analysis Conference, Orlando, FL, 1997; 257-263.

[32] Ülker-Kaustell M, and Karoumi R. Application of the continuous wavelet transform on the free vibrations of a steel-concrete composite railway bridge. Engineering Structures 2011; 33: 911-919.

[33] Gomez HC, Ulusoy HS, and Feng MQ. Variation of modal parameters of a highway bridge extracted from six earthquake records. Earthquake Engineering and Structural Dynamics 2013; 42(4), 565-579.

[34] Feng M Q, Kim DK, Yi JH, and Chen Y. Baseline models for bridge performance monitoring. Journal of Engineering Mechanics, ASCE 2004; 130(5): 562-569. 
[35] Petroff, SM, Halling, MW, and Barr, PJ. Vibrational testing, modeling and monitoring of two highway bridges. 15th World Conference on Earthquake Engineering, Lisbon, Portugal 2012; 1-10.

[36] Londono NA, Lau DT, and Rahman M. Characteristics of dynamic monitoring data and observed behaviour of the Confederation Bridge due to operational load variations, Canadian Journal for Civil Engineering 2013; 40(5): 393-409.

[37] Littler JD. An assessment of some of the different methods for estimating damping from full-scale testing. Journal of Wind Engineering and Industrial Aerodynamics 1995; 57(23): 179-189.

[38] Farrar CR, Duffey T, Cornwell PJ, and Doebling SW. Excitation methods for bridge structures. 17th International Modal Analysis Conference, Kissimmee, FL 1999; 1: 1063-1068.

[39] Ma QT, Omenzetter P, Ingham JM, Butterworth JW, and Pender MJ. Overview of NZNEES@Auckland, New Zealand Society for Earthquake Engineering Annual Technical Conference, Palmerston North, 2007; 1-8.

[40] Haritos N. Low cost accelerometer sensors - applications and challenges. Australian Earthquake Engineering Society Conference, Newcastle, Australia, 2009, 1-11.

[41] Beskhyroun S, and Ma QT. Low-cost accelerometers for experimental modal analysis. 15th World Conference on Earthquake Engineering, Lisbon, Portugal, 2012.

[42] Chen X, Omenzetter P, and Beskhyroun S. Dynamic testing and long term monitoring of a twelve span viaduct. Key Engineering Materials 2013; 569-570: 342-349.

[43] Felber AJ, and Ventura CE, Frequency domain analysis of the ambient vibration data of the Queensborough Bridge main span. 14th International Modal Analysis Conference, Dearborn, MI 1996; 459-465.

[44] Bates DM, and Wattes DG, Nonlinear regression analysis and its applications, Wiley, Hoboken, NJ 2007.

[45] de Boor C, A practical guide to splines, Springer-Verlag, Germany 1978.

[46] Allemang RJ, and Brown DL. A correlation coefficient for modal vector analysis. 1st International Modal Analysis Conference, Orlando, FL 1982; 110-116.

[47] Liu C, and De Wolf JT. Effect of temperature on modal variability of a curved concrete bridge under ambient loads. Journal of Structural Engineering, ASCE 2007; 133: 17421751. 
[48] Cury A, Cremona C and Dumoulin J. Long-term monitoring of a PSC box girder bridge: operational modal analysis, data normalization and structural modification assessment. Mechanical Systems and Signal Processing 2012; 33: 13-37.

[49] $\mathrm{Fu} \mathrm{Y}$ and De Wolf J. Effect of differential temperature on a curved post-tensioned concrete bridge. Advances in Structural Engineering 2004; 7: 385-397.

[50] ANSYS. ANSYS Workbench User's Manual Version 13.0, Mechanical APDL, Canonsburg, PA; 2012.

[51] Grimes RG, Lewis JG, and Simon HD. A shifted block Lanczos algorithm for solving sparse symmetrical generalized eigenproblems. SIAM Journal on Matrix Analysis and Applications 1994; 15(1): 228-272.

[52] Zivanovic S, Pavic A, and Reynolds P. Vibration serviceability of footbridges under human-induced excitation: a literature review. Journal of Sound and Vibration 2005; 279: $1-74$. 
Table 1. Testing programme for vertical shaker.

\begin{tabular}{|c|c|c|c|c|c|}
\hline $\begin{array}{l}\text { Excitation } \\
\text { direction }\end{array}$ & $\begin{array}{l}\text { Frequency } \\
\text { range } \\
(\mathrm{Hz})\end{array}$ & $\begin{array}{c}\text { Number of masses } \\
\text { per shaft }\end{array}$ & $\begin{array}{c}\text { Mass-eccentricity } \\
(\mathrm{kg}-\mathrm{m})\end{array}$ & $\begin{array}{l}\text { Frequency } \\
\text { increment } \\
(\mathrm{Hz})\end{array}$ & $\begin{array}{l}\text { Holding } \\
\text { time } \\
\text { (s) }\end{array}$ \\
\hline \multicolumn{6}{|c|}{ Preliminary fast, wide band, large step sweep } \\
\hline Vertical & $0.0-10.0$ & 1 small mass & 0.245 & 0.1 & 20 \\
\hline \multicolumn{6}{|c|}{ Series of detailed, narrow band, small step sweeps } \\
\hline Vertical & $2.80-3.40$ & 1 small mass & 0.245 & 0.01 & 60 \\
\hline Vertical & $2.80-3.40$ & \multirow{2}{*}{$\begin{array}{c}1 \text { big mass } \\
1 \text { big plus } 1 \text { small } \\
\text { mass }\end{array}$} & 0.918 & 0.01 & 60 \\
\hline Vertical & $2.80-3.40$ & & 1.041 & 0.01 & 60 \\
\hline Vertical & $2.80-3.40$ & 1 small mass & 0.245 & 0.01 & 60 \\
\hline & & $\begin{array}{l}\text { for } \mathrm{fr} \\
6.90\end{array}$ & $\begin{array}{l}3.56-3.96 \mathrm{~Hz}, 4 \\
60-8.20 \mathrm{~Hz}\end{array}$ & $.40 \mathrm{~Hz}$ & $.90 \mathrm{~Hz}$ \\
\hline
\end{tabular}

Chen et al. 
Table 2. Testing programme for lateral shaker.

\begin{tabular}{cccccc}
\hline $\begin{array}{c}\text { Excitation } \\
\text { direction }\end{array}$ & $\begin{array}{c}\text { Frequency } \\
\text { range } \\
(\mathrm{Hz})\end{array}$ & $\begin{array}{c}\text { Number of masses } \\
\text { per shaft }\end{array}$ & $\begin{array}{c}\text { Mass- } \\
\text { eccentricity } \\
(\mathrm{kg}-\mathrm{m})\end{array}$ & $\begin{array}{c}\text { Frequency } \\
\text { increment } \\
(\mathrm{Hz})\end{array}$ & $\begin{array}{c}\text { Holding } \\
\text { time } \\
(\mathrm{s})\end{array}$ \\
\hline \multicolumn{7}{c}{ Preliminary fast, wide band, large step sweep } \\
\hline Lateral & $0.0-10.0$ & 1 small mass & 0.245 & 0.1 & 20 \\
\hline \multicolumn{7}{c}{ Series of detailed, narrow band, small step sweeps } \\
\hline Lateral & $1.60-1.95$ & 1 small mass & 0.245 & 0.01 & 60 \\
Lateral & $1.60-1.95$ & 1 big mass & 0.918 & 0.01 & 60 \\
Lateral & $1.60-1.95$ & 2 big masses & 1.633 & 0.01 & 60 \\
Lateral & $1.60-1.95$ & 3 big masses & 2.296 & 0.01 & 60 \\
Lateral & $1.60-1.95$ & 4 big masses & 2.806 & 0.01 & 60 \\
Lateral & $1.60-1.95$ & 5 big masses & 3.316 & 0.01 & 60 \\
Lateral & $1.60-1.95$ & 6 big masses & 3.724 & 0.01 & 60 \\
Lateral & $1.60-1.95$ & 7 big masses & 4.286 & 0.01 & 60 \\
Lateral & $1.60-1.95$ & 8 big masses & 4.592 & 0.01 & 60 \\
Lateral & $1.60-1.95$ & 1 small mass & 0.245 & 0.01 & 60 \\
\hline Similar series of detailed tests for frequency ranges $2.20-2.90 \mathrm{~Hz}, 3.20-3.9 \mathrm{~Hz}, 6.20-6.80$ \\
\multicolumn{7}{c}{} \\
\hline \multicolumn{7}{c}{ Hz, 7.4-8 Hz and 9-9.9 Hz }
\end{tabular}

Chen et al. 
Table 3. Modes identified from preliminary sweeps and peak picking.

\begin{tabular}{|c|c|c|c|c|}
\hline \multirow{2}{*}{ Mode } & \multirow{2}{*}{$\begin{array}{c}\text { Frequency } \\
(\mathrm{Hz})\end{array}$} & \multicolumn{3}{|c|}{ Mode coupling ratio } \\
\hline & & $\mathrm{V}$ & $\mathrm{T}$ & $\mathrm{L}$ \\
\hline \multicolumn{5}{|c|}{ Vertical modes } \\
\hline V1 & 3.18 & 1 & 0.03 & 0.08 \\
\hline $\mathrm{V} 2$ & 3.91 & 1 & 0.03 & 0.08 \\
\hline V3 & 4.19 & 1 & 0.16 & 0.07 \\
\hline V4 & 4.79 & 1 & 0.17 & 0.13 \\
\hline V5 & 5.66 & 1 & 0.41 & 0.35 \\
\hline V6 & 7.15 & 1 & 0.06 & 0.09 \\
\hline \multicolumn{5}{|c|}{ Mixed vertical-torsional mode } \\
\hline \multirow{4}{*}{ V7/T1 } & \multirow{4}{*}{7.92} & \multicolumn{3}{|c|}{ North of hinge } \\
\hline & & 1 & 0.09 & 0.21 \\
\hline & & \multicolumn{3}{|c|}{ South of hinge } \\
\hline & & 0.02 & 0.57 & 0.08 \\
\hline \multicolumn{5}{|c|}{ Lateral modes } \\
\hline L1 & 1.86 & 0.26 & $(0.11)^{3}$ & 1 \\
\hline $\mathrm{L} 2$ & 2.56 & 0.21 & $(0.20)$ & 1 \\
\hline L3 & 3.65 & 0.27 & $(0.08)$ & 1 \\
\hline L4 & 4.54 & 0.13 & $(0.15)$ & 1 \\
\hline L5 & 5.57 & 0.45 & $(0.33)$ & 1 \\
\hline L6 & 6.61 & 0.32 & $(0.15)$ & 1 \\
\hline L7 & 7.61 & 0.42 & $(0.24)$ & 1 \\
\hline L8 & 9.32 & 0.48 & $(0.17)$ & 1 \\
\hline
\end{tabular}

* Values in () from FE model.

Chen et al. 
Table 4. Dependence of modal frequencies and damping ratios on forcing and response amplitude for vertical and vertical-torsional modes.

\begin{tabular}{|c|c|c|c|c|c|c|c|c|c|}
\hline Mode & $\begin{array}{c}\text { Date } \\
(\mathrm{dd} / \mathrm{mm} / \mathrm{yy})\end{array}$ & $\begin{array}{l}\text { Start-end time } \\
\text { (hh:mm:ss) }\end{array}$ & $\begin{array}{c}\text { Mean } \\
\text { ambient } \\
\text { temperature } \\
\left({ }^{\circ} \mathrm{C}\right)\end{array}$ & Mass per shaft & $\begin{array}{c}\text { Force } \\
\text { amplitude } \\
(\mathrm{kN})\end{array}$ & $\begin{array}{l}\text { Displacement } \\
\text { amplitude } \\
\text { (mm) }\end{array}$ & $\begin{array}{l}\text { Modal } \\
\text { frequency } \\
\quad(\mathrm{Hz})\end{array}$ & $\begin{array}{l}\text { Damping } \\
\text { ratio } \\
(\%)\end{array}$ & $\mathrm{MAC}^{\mathrm{a}}$ \\
\hline \multirow[t]{4}{*}{ V1 } & $23 / 05 / 13$ & $08: 15: 34-08: 40: 15$ & 18.00 & 1 small & 0.952 & 0.202 & 3.171 & 0.99 & - \\
\hline & & $08: 50: 40-09: 22: 12$ & 18.00 & $1 \mathrm{big}$ & 3.550 & 0.757 & 3.161 & 1.63 & 0.999 \\
\hline & & $09: 31: 39-10: 02: 16$ & 18.25 & 1 big +1 small & 4.021 & 0.858 & 3.160 & 1.65 & 0.998 \\
\hline & & $10: 15: 48-10: 41: 32$ & 19.50 & 1 small (final) & 0.954 & 0.192 & 3.173 & 1.05 & 0.998 \\
\hline \multirow[t]{4}{*}{$\mathrm{V} 2$} & $23 / 05 / 13$ & $10: 55: 24-11: 23: 49$ & 20.50 & 1 small & 1.406 & 0.118 & 3.852 & 0.66 & - \\
\hline & & $11: 35: 18-12: 10: 31$ & 21.00 & $1 \mathrm{big}$ & 5.248 & 0.562 & 3.843 & 0.79 & 0.997 \\
\hline & & $12: 20: 36-12: 51: 09$ & 22.00 & $1 \mathrm{big}+1$ small & 5.937 & 0.659 & 3.840 & 0.79 & 0.996 \\
\hline & & $13: 03: 51-13: 32: 29$ & 23.50 & 1 small (final) & 1.404 & 0.128 & 3.850 & 0.71 & 0.998 \\
\hline \multirow[t]{4}{*}{ V3 } & $23 / 05 / 13$ & $13: 43: 47-14: 16: 17$ & 23.50 & 1 small & 1.643 & 0.082 & 4.164 & 0.56 & - \\
\hline & & $14: 30: 27-15: 05: 09$ & 23.50 & $1 \mathrm{big}$ & 6.138 & 0.396 & 4.156 & 0.65 & 0.998 \\
\hline & & $15: 16: 37-15: 48: 34$ & 23.50 & $1 \mathrm{big}+1$ small & 6.948 & 0.466 & 4.154 & 0.63 & 0.998 \\
\hline & & $15: 56: 19-16: 28: 26$ & 22.00 & 1 small (final) & 1.643 & 0.096 & 4.164 & 0.57 & 0.998 \\
\hline \multirow[t]{4}{*}{ V4 } & $24 / 05 / 13$ & $07: 25: 31-07: 50: 58$ & 18.50 & 1 small & 2.138 & 0.030 & 4.750 & 0.56 & - \\
\hline & & $08: 01: 34-08: 32: 54$ & 19.00 & $1 \mathrm{big}$ & 7.985 & 0.164 & 4.741 & 0.56 & 0.997 \\
\hline & & $08: 40: 15-09: 08: 24$ & 20.00 & $1 \mathrm{big}+1$ small & 9.043 & 0.190 & 4.739 & 0.56 & 0.998 \\
\hline & & 09:20:30-09:42:12 & 21.00 & 1 small (final) & 2.140 & 0.036 & 4.753 & 0.55 & 0.998 \\
\hline \multirow[t]{4}{*}{ V6 } & $24 / 05 / 13$ & $12: 42: 36-13: 11: 53$ & 22.50 & 1 small & 4.831 & 0.102 & 7.140 & 1.46 & - \\
\hline & & $13: 26: 51-14: 01: 24$ & 22.50 & $1 \mathrm{big}$ & 17.957 & 0.530 & 7.109 & 1.59 & 0.998 \\
\hline & & $14: 12: 44-14: 52: 08$ & 23.00 & $1 \mathrm{big}+1$ small & 20.291 & 0.612 & 7.099 & 1.63 & 0.998 \\
\hline & & $15: 03: 21-15: 36: 17$ & 23.00 & 1 small (final) & 4.829 & 0.098 & 7.139 & 1.50 & 0.997 \\
\hline \multirow[t]{4}{*}{$\mathrm{V} 7 / \mathrm{T} 1$} & $24 / 05 / 13$ & $15: 44: 39-16: 15: 48$ & 22.00 & 1 small & 5.933 & 0.071 & 7.913 & 1.67 & - \\
\hline & & $16: 28: 50-16: 55: 18$ & 21.00 & $1 \mathrm{big}$ & 21.668 & 0.353 & 7.809 & 1.76 & 0.997 \\
\hline & & 17:04:54-17:39:09 & 20.50 & $1 \mathrm{big}+1$ small & 24.480 & 0.407 & 7.759 & 1.85 & 0.996 \\
\hline & & $17: 51: 35-18: 29: 06$ & 19.50 & 1 small (final) & 5.931 & 0.077 & 7.912 & 1.70 & 0.996 \\
\hline
\end{tabular}

${ }^{\mathrm{a}}$ With respect to the lowest excitation level

Chen et al. 
Table 5. Dependence of modal frequencies and damping ratios on forcing and response amplitude for lateral modes.

\begin{tabular}{|c|c|c|c|c|c|c|c|c|c|}
\hline Mode & $\begin{array}{c}\text { Date } \\
\text { (dd/mm/yy) }\end{array}$ & $\begin{array}{l}\text { Start-end time } \\
\text { (hh:mm:ss) }\end{array}$ & $\begin{array}{c}\text { Mean ambient } \\
\text { temperature } \\
\left({ }^{\circ} \mathrm{C}\right)\end{array}$ & Mass per shaft & $\begin{array}{c}\text { Force } \\
\text { amplitude } \\
(\mathrm{kN})\end{array}$ & $\begin{array}{l}\text { Displacement } \\
\text { amplitude } \\
(\mathrm{mm})\end{array}$ & $\begin{array}{c}\text { Modal } \\
\text { frequency } \\
(\mathrm{Hz})\end{array}$ & $\begin{array}{c}\text { Damping ratio } \\
(\%)\end{array}$ & $\mathrm{MAC}^{\mathrm{a}}$ \\
\hline \multirow[t]{10}{*}{ L1 } & $25 / 05 / 13$ & 07:31:06-07:56:19 & 17.00 & 1 small & 0.330 & 0.077 & 1.866 & 0.82 & - \\
\hline & & $08: 12: 40-08: 50: 28$ & 17.25 & $1 \mathrm{big}$ & 1.202 & 0.308 & 1.839 & 1.13 & 0.999 \\
\hline & & $09: 05: 24-09: 40: 16$ & 17.50 & 2 big & 2.069 & 0.531 & 1.810 & 1.16 & 0.999 \\
\hline & & $09: 52: 32-10: 31: 29$ & 18.75 & 3 big & 2.869 & 0.785 & 1.797 & 1.12 & 0.998 \\
\hline & & $10: 43: 05-11: 21: 37$ & 20.00 & 4 big & 3.483 & 1.003 & 1.791 & 1.11 & 0.999 \\
\hline & & $11: 30: 14-12: 09: 46$ & 21.00 & 5 big & 4.100 & 1.198 & 1.788 & 1.13 & 0.998 \\
\hline & & $12: 17: 33-12: 45: 57$ & 21.50 & 6 big & 4.581 & 1.366 & 1.783 & 1.16 & 0.998 \\
\hline & & $12: 56: 39-13: 41: 08$ & 22.00 & 7 big & 5.233 & 1.573 & 1.777 & 1.13 & 0.997 \\
\hline & & $13: 52: 55-14: 33: 43$ & 24.00 & 8 big & 5.604 & 1.660 & 1.776 & 1.18 & 0.998 \\
\hline & & $14: 43: 29-15: 18: 25$ & 23.50 & 1 small (final) & 0.330 & 0.084 & 1.865 & 0.88 & 0.998 \\
\hline \multirow[t]{8}{*}{ L2 } & $26 / 05 / 13$ & $07: 48: 19-08: 28: 37$ & 17.00 & 1 small & 0.619 & 0.054 & 2.556 & 1.27 & - \\
\hline & & $08: 41: 26-09: 21: 42$ & 17.25 & $1 \mathrm{big}$ & 2.267 & 0.223 & 2.526 & 1.85 & 0.999 \\
\hline & & $09: 34: 53-10: 16: 07$ & 18.00 & 2 big & 3.926 & 0.469 & 2.493 & 1.82 & 0.999 \\
\hline & & $10: 28: 09-11: 10: 15$ & 19.00 & 3 big & 5.489 & 0.719 & 2.486 & 1.74 & 0.996 \\
\hline & & $11: 24: 47-12: 08: 14$ & 20.50 & 4 big & 6.700 & 0.853 & 2.484 & 1.82 & 0.995 \\
\hline & & $12: 25: 03-13: 02: 49$ & 21.00 & 5 big & 7.852 & 1.068 & 2.474 & 1.83 & 0.998 \\
\hline & & $13: 18: 59-14: 01: 36$ & 21.50 & 6 big & 8.726 & 1.148 & 2.461 & 2.03 & 0.997 \\
\hline & & $14: 14: 48-14: 56: 24$ & 21.75 & 1 small (final) & 0.620 & 0.052 & 2.559 & 1.32 & 0.998 \\
\hline \multirow[t]{7}{*}{ L6 } & $27 / 05 / 13$ & $08: 16: 27-08: 54: 46$ & 18.00 & 1 small & 4.129 & 0.010 & 6.602 & 1.88 & - \\
\hline & & $09: 09: 14-09: 51: 32$ & 19.00 & $1 \mathrm{big}$ & 15.293 & 0.051 & 6.561 & 1.98 & 0.998 \\
\hline & & $10: 07: 18-10: 53: 21$ & 19.25 & 2 big & 26.924 & 0.101 & 6.536 & 2.16 & 0.997 \\
\hline & & $11: 04: 00-11: 43: 52$ & 20.00 & 3 big & 37.634 & 0.151 & 6.515 & 2.32 & 0.999 \\
\hline & & $11: 55: 09-12: 38: 47$ & 21.50 & 4 big & 45.264 & 0.200 & 6.484 & 2.41 & 0.997 \\
\hline & & $12: 47: 53-13: 25: 34$ & 21.50 & 5 big & 53.530 & 0.242 & 6.469 & 2.44 & 0.996 \\
\hline & & $13: 37: 58-14: 18: 40$ & 22.00 & 1 small (final) & 4.127 & 0.008 & 6.600 & 1.91 & 0.997 \\
\hline \multirow[t]{3}{*}{ L7 } & $25 / 05 / 13$ & $15: 32: 55-16: 04: 58$ & 23.50 & 1 small & 5.560 & 0.008 & 7.660 & 1.74 & - \\
\hline & & $16: 18: 36-16: 56: 37$ & 23.00 & $1 \mathrm{big}$ & 20.745 & 0.034 & 7.641 & 2.00 & 0.995 \\
\hline & & $17: 11: 51-17: 48: 07$ & 22.00 & 1 small (final) & 5.556 & 0.011 & 7.658 & 1.75 & 0.997 \\
\hline \multirow[t]{3}{*}{ L8 } & $26 / 05 / 13$ & $15: 05: 31-15: 43: 34$ & 22.50 & 1 small & 8.425 & 0.019 & 9.430 & 2.30 & - \\
\hline & & $15: 53: 53-16: 32: 42$ & 22.00 & $1 \mathrm{big}$ & 31.452 & 0.108 & 9.409 & 2.45 & 0.996 \\
\hline & & $16: 41: 04-17: 17: 34$ & 21.50 & 1 small (final) & 8.418 & 0.018 & 9.426 & 2.31 & 0.996 \\
\hline
\end{tabular}

Chen et al. 
Table 6. Correlation between experimental and numerical modal parameters.

\begin{tabular}{ccccc}
\hline Mode & \multicolumn{3}{c}{ Frequency } & MAC \\
\cline { 2 - 4 } & $\begin{array}{c}\text { Test } \\
(\mathrm{Hz})\end{array}$ & $\begin{array}{c}\text { FE model } \\
(\mathrm{Hz})\end{array}$ & $\begin{array}{c}\text { Error }^{\mathrm{a}} \\
(\%)\end{array}$ & \\
\hline V1 & 3.171 & 3.169 & -0.1 & 0.988 \\
V2 & 3.852 & 3.946 & 2.4 & 0.937 \\
V3 & 4.164 & 4.169 & 0.1 & 0.932 \\
V4 & 4.750 & 4.806 & 1.2 & 0.871 \\
V5 & 5.640 & 5.548 & -1.6 & 0.580 \\
V6 & 7.140 & 7.153 & 0.2 & 0.908 \\
\hline \multicolumn{5}{c}{ Mixed vertical-torsional mode } \\
\hline V7/T1 & 8.433 & 6.6 & 0.472 \\
\hline L1 & 7.913 & Lateral modes & 0.967 \\
L2 & 1.866 & 1.869 & 0.2 & 0.841 \\
L3 & 2.556 & 2.592 & 1.4 & 0.655 \\
L4 & 3.638 & 3.641 & 0.1 & 0.886 \\
L5 & 4.487 & 4.337 & -3.3 & 0.833 \\
L6 & 5.570 & 5.914 & 6.2 & 0.837 \\
L7 & 6.602 & 7.430 & 12.5 & 0.639 \\
L8 & 7.660 & 8.484 & 10.8 & \\
\hline
\end{tabular}

${ }^{\mathrm{a}}$ With respect to experimental frequency

Chen et al. 
Table 7. Natural frequency change due to damage vs. due to response level and damage detectability.

\begin{tabular}{|c|c|c|c|c|c|}
\hline \multirow{2}{*}{ Mode } & \multicolumn{3}{|c|}{$\begin{array}{l}\text { Frequency drop } \\
(\mathrm{Hz})\end{array}$} & \multicolumn{2}{|c|}{$\begin{array}{c}\text { Damage detection } \\
(\mathrm{Y} / \mathrm{N})\end{array}$} \\
\hline & Scenario 1 & Scenario 2 & $\begin{array}{l}\text { Amplitude } \\
\text { dependent }\end{array}$ & Scenario 1 & Scenario 2 \\
\hline \multicolumn{6}{|c|}{ Vertical modes } \\
\hline V1 & 0.021 & - & 0.011 & $\mathrm{Y}$ & - \\
\hline $\mathrm{V} 2$ & 0.008 & - & 0.012 & $\mathrm{~N}$ & - \\
\hline V3 & 0.014 & - & 0.010 & $\mathrm{Y}$ & - \\
\hline V4 & 0.005 & - & 0.011 & $\mathrm{~N}$ & - \\
\hline V6 & 0.033 & - & 0.041 & $\mathrm{~N}$ & - \\
\hline \multicolumn{6}{|c|}{ Mixed vertical-torsional mode } \\
\hline V7/T1 & 0.026 & - & 0.155 & $\mathrm{~N}$ & - \\
\hline \multicolumn{6}{|c|}{ Lateral modes } \\
\hline L1 & - & 0.033 & 0.090 & - & $\mathrm{N}$ \\
\hline $\mathrm{L} 2$ & - & 0.013 & 0.114 & - & $\mathrm{N}$ \\
\hline L6 & - & 0.011 & 0.133 & - & $\mathrm{N}$ \\
\hline L7 & - & 0.002 & 0.020 & - & $\mathrm{N}$ \\
\hline L8 & - & 0.005 & 0.021 & - & $\mathrm{N}$ \\
\hline
\end{tabular}

Chen et al. 


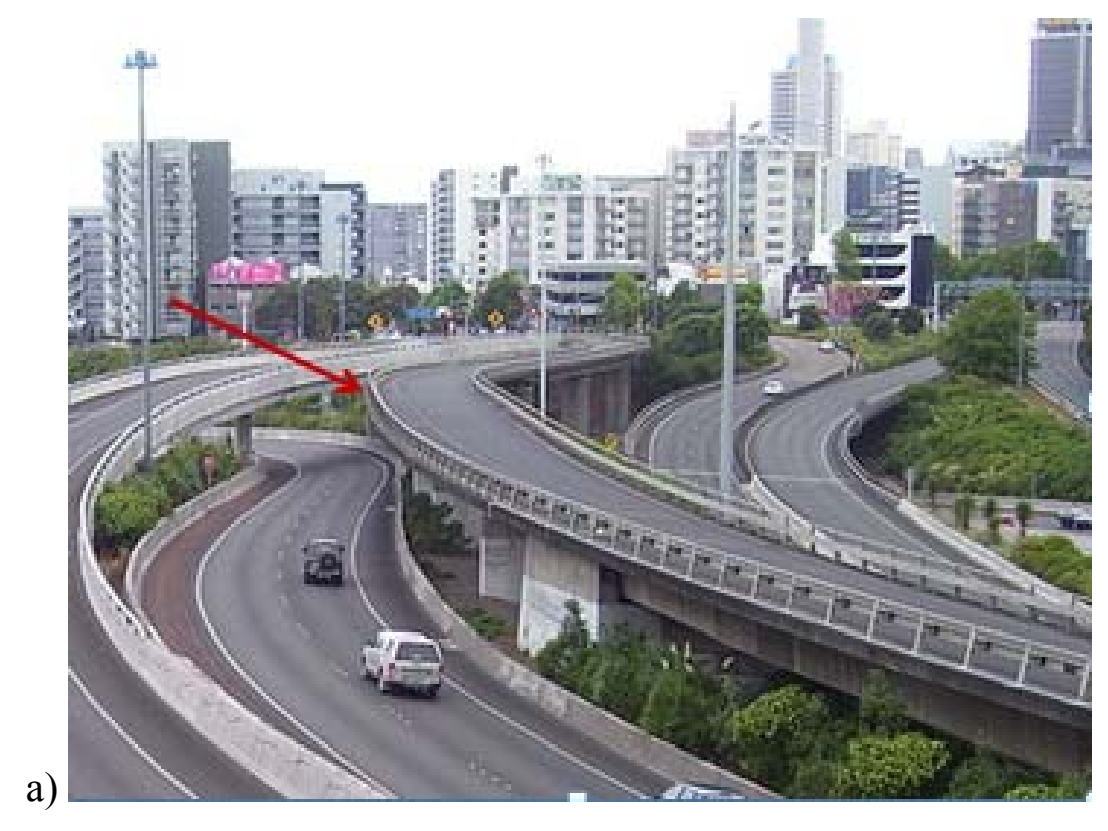

b)

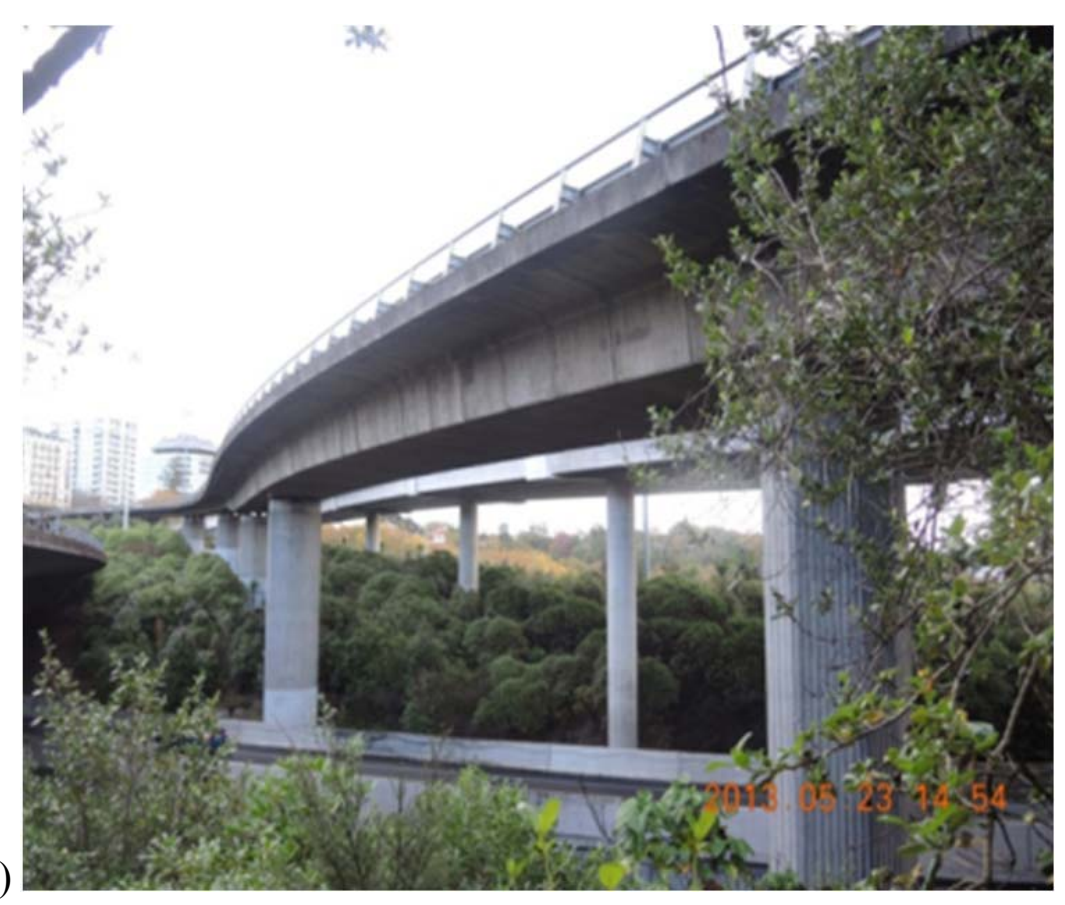

Figure 1. Nelson St. off-ramp bridge: aerial view looking South (bridge indicated by arrow), and b) side view of the longest span looking North.

Chen et al. 


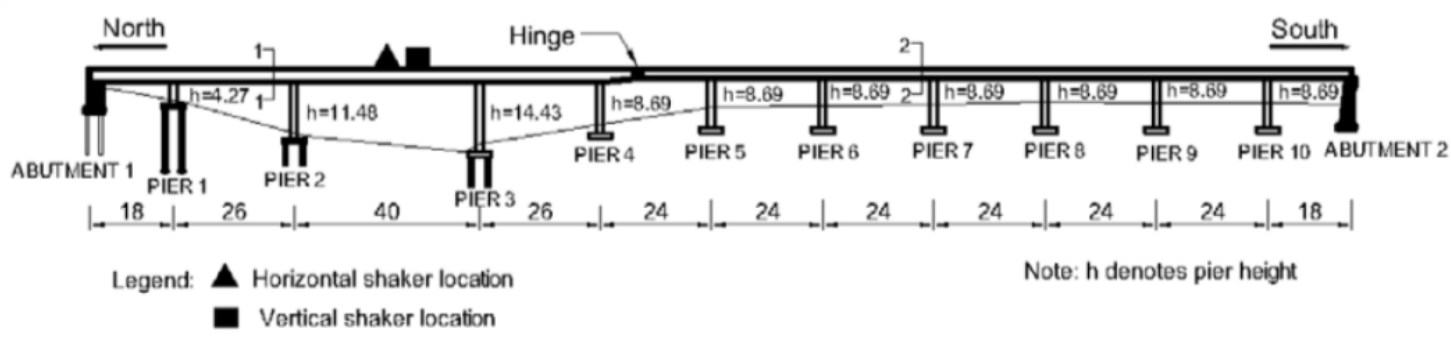

Figure 2. General structural arrangement of Nelson St. off-ramp bridge (all dimensions in m).

Chen et al. 

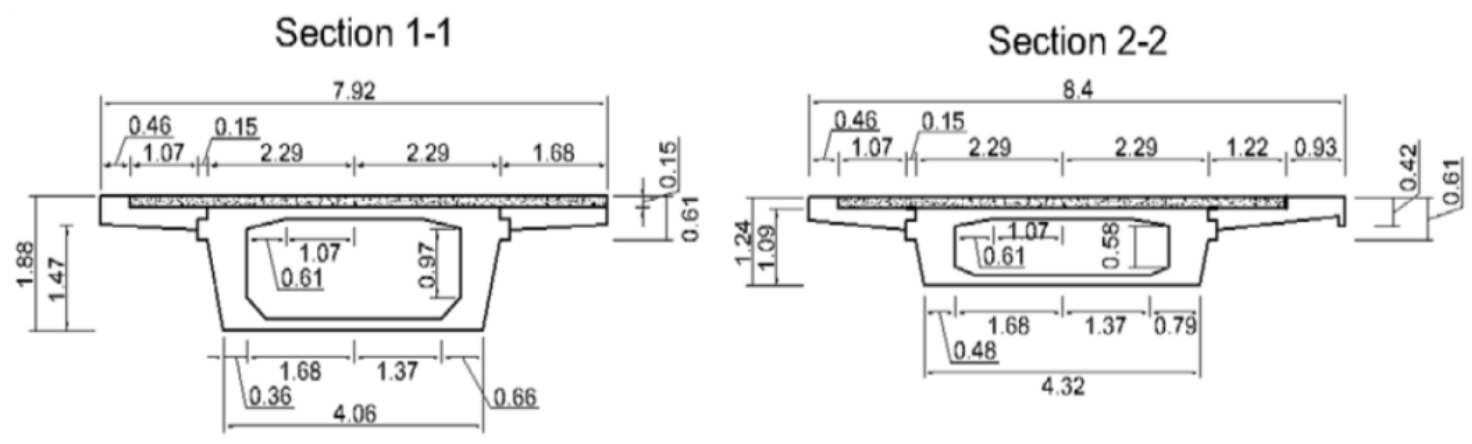

Figure 3. Two typical cross-sections (all dimensions in m; refer to Fig. 2 for their location).

Chen et al. 


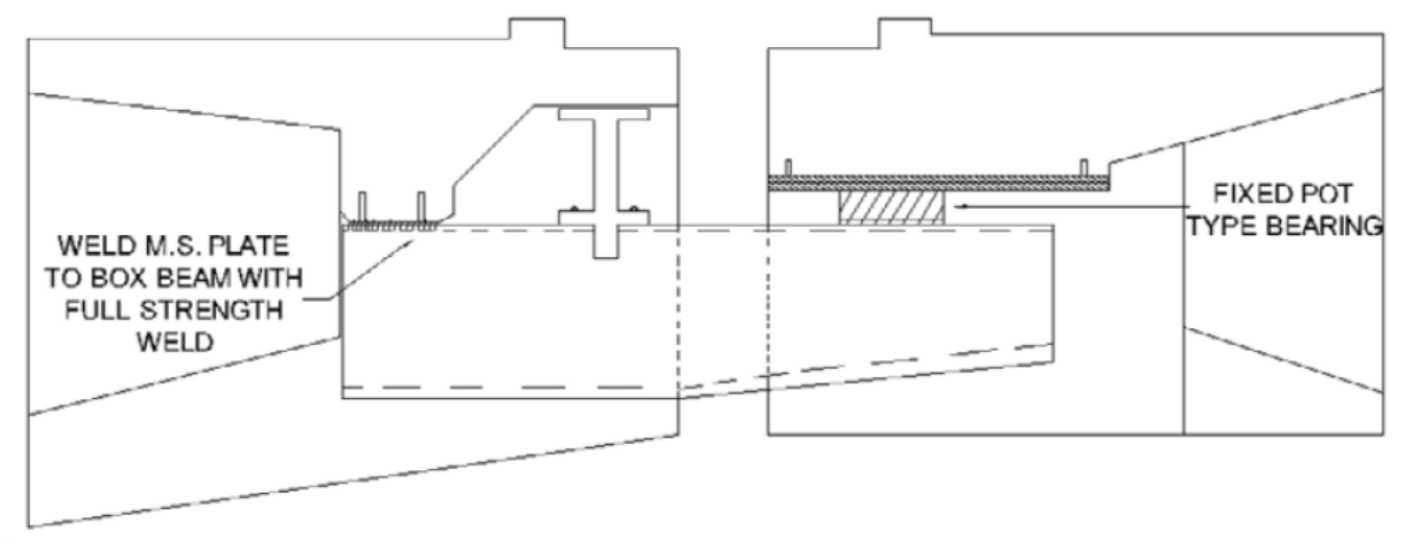

Figure 4. Hinge.

Chen et al. 


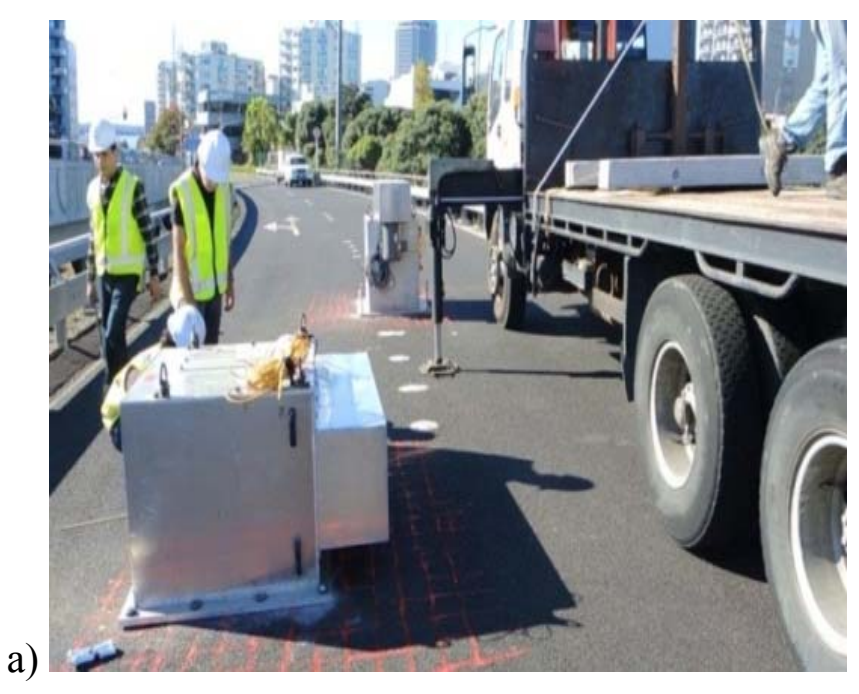

b)

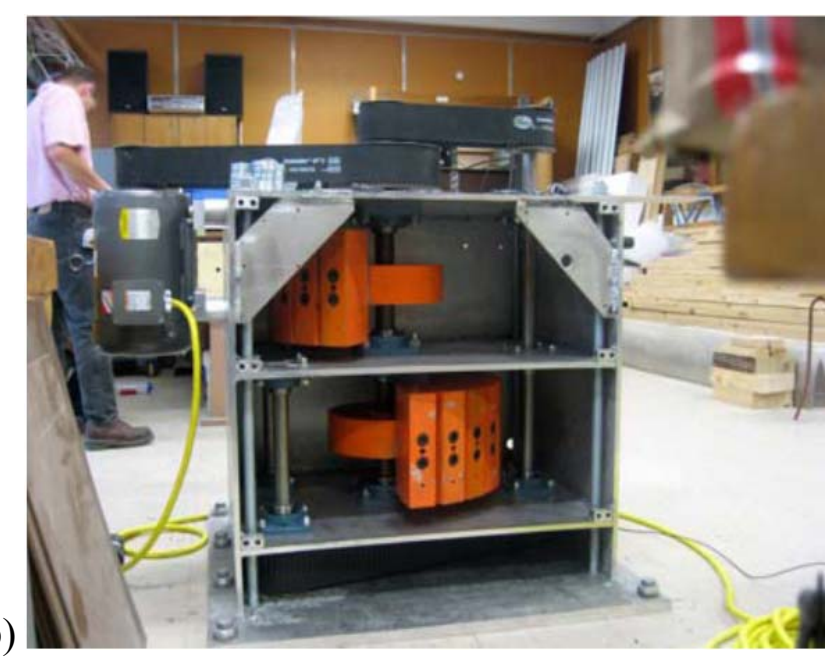

Figure 5. Eccentric mass shakers: a) anchored to the bridge deck (shaker in the front is for vertical and shaker at the back is for lateral excitation), and b) inside of shaker showing rotating masses on flywheels.

Chen et al. 


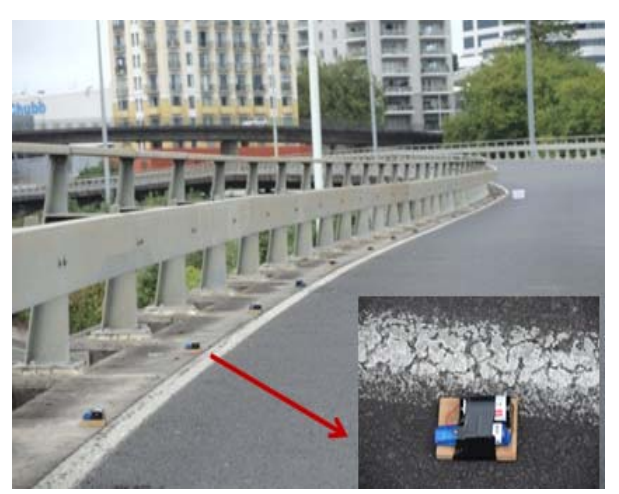

Figure 6. MEMS tri-axial accelerometers on the bridge deck (inset: accelerometer/D-cell battery unit).

Chen et al. 


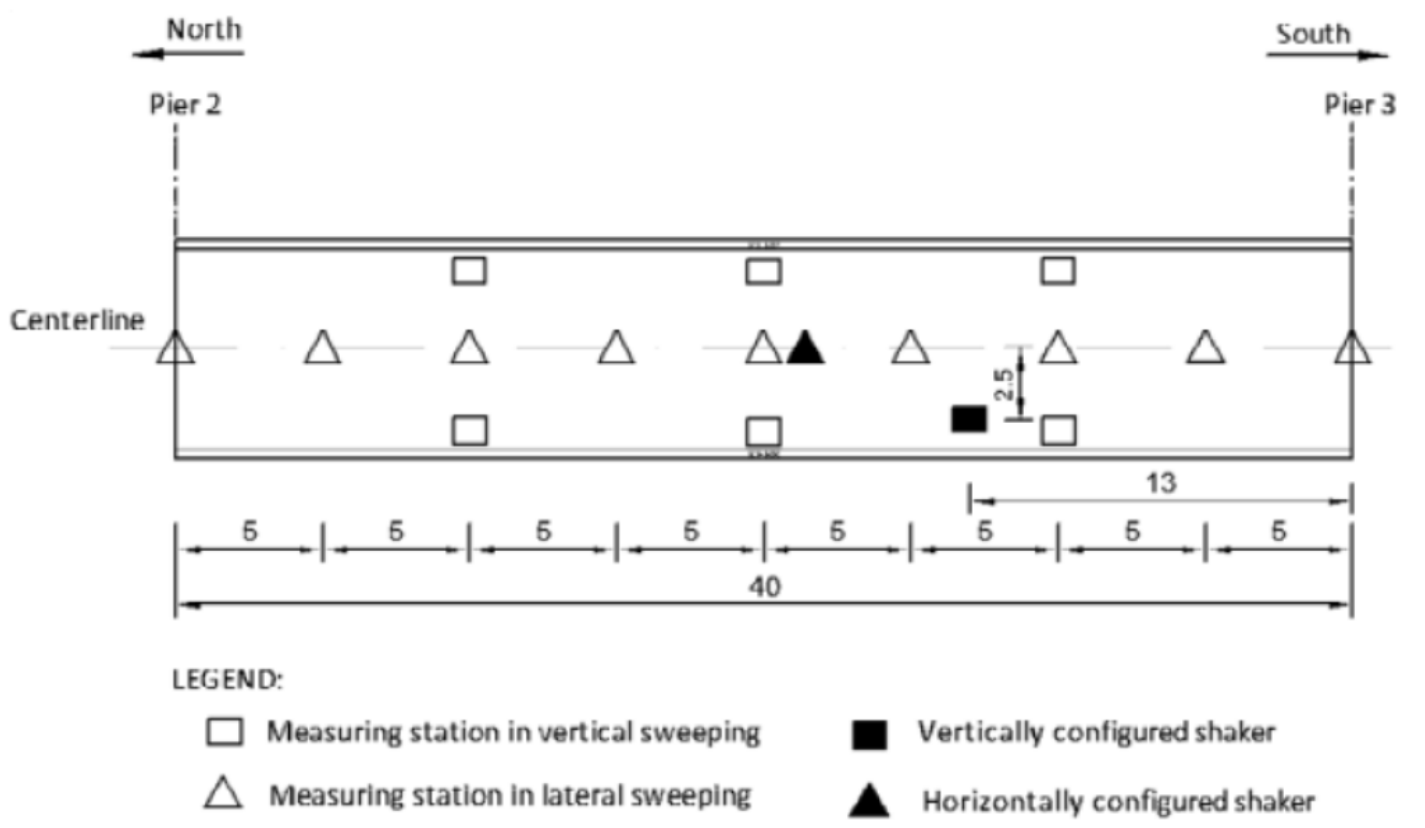

Figure 7. Instrumentation layout on the longest span (all dimensions are in $\mathrm{m}$ ).

Chen et al. 


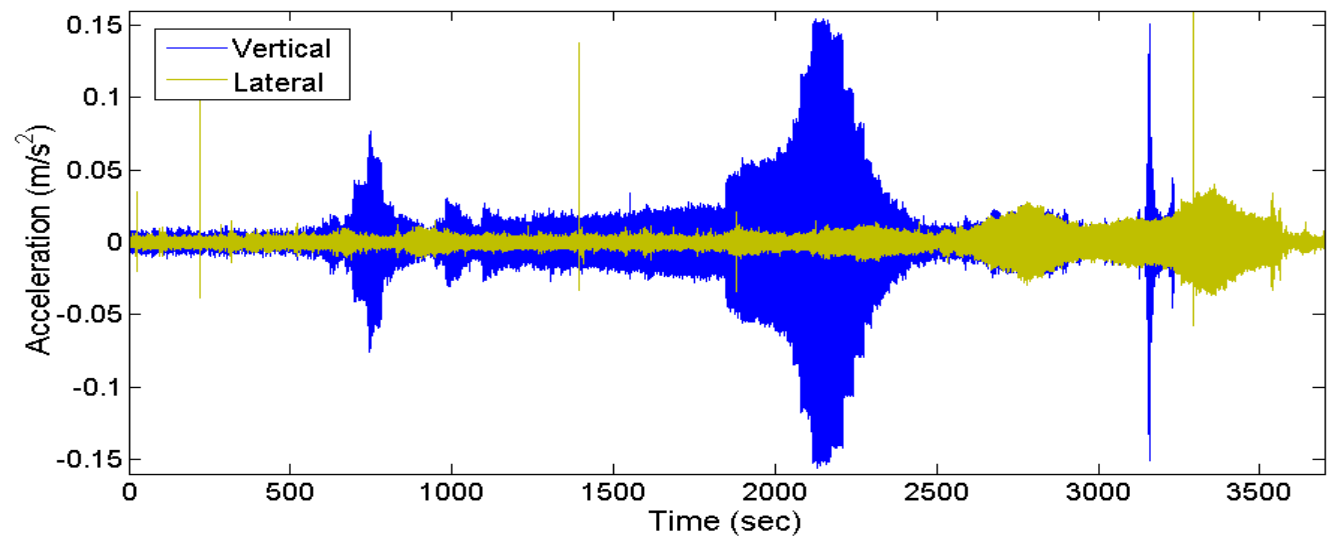

Figure 8. Vertical and lateral acceleration responses recorded during preliminary, fast frequency sweeps.

Chen et al. 


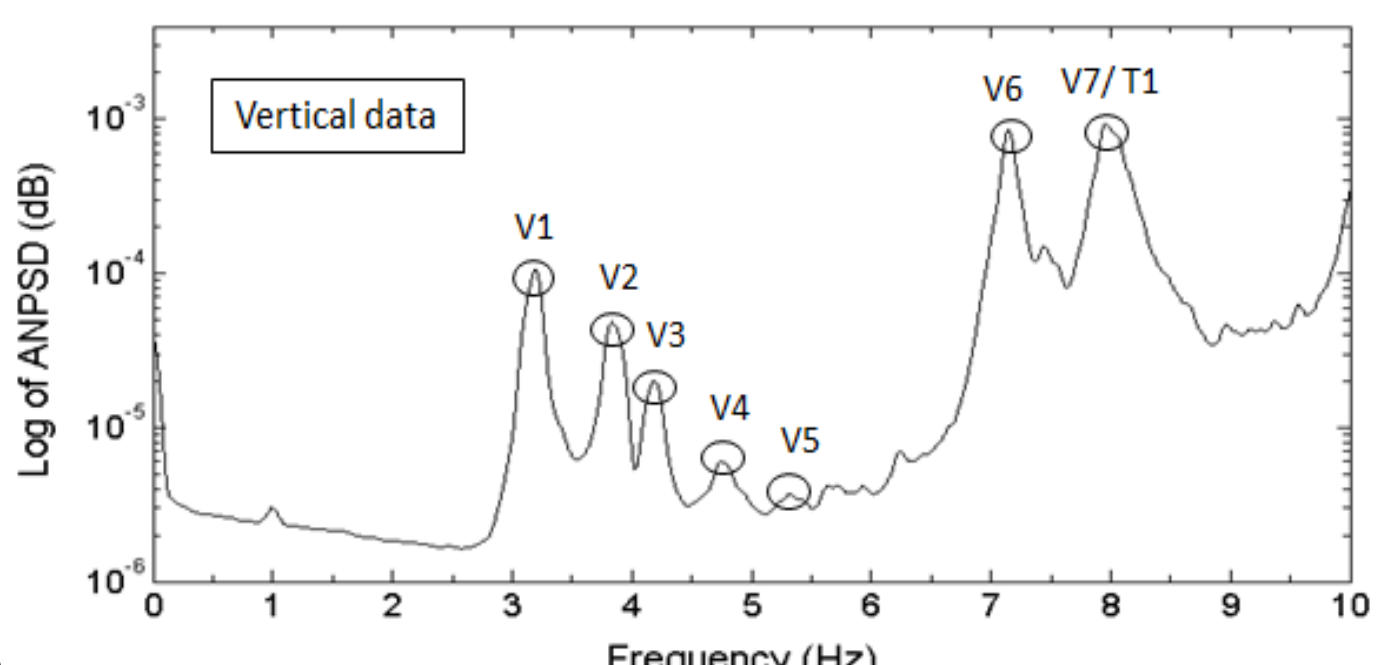

a)

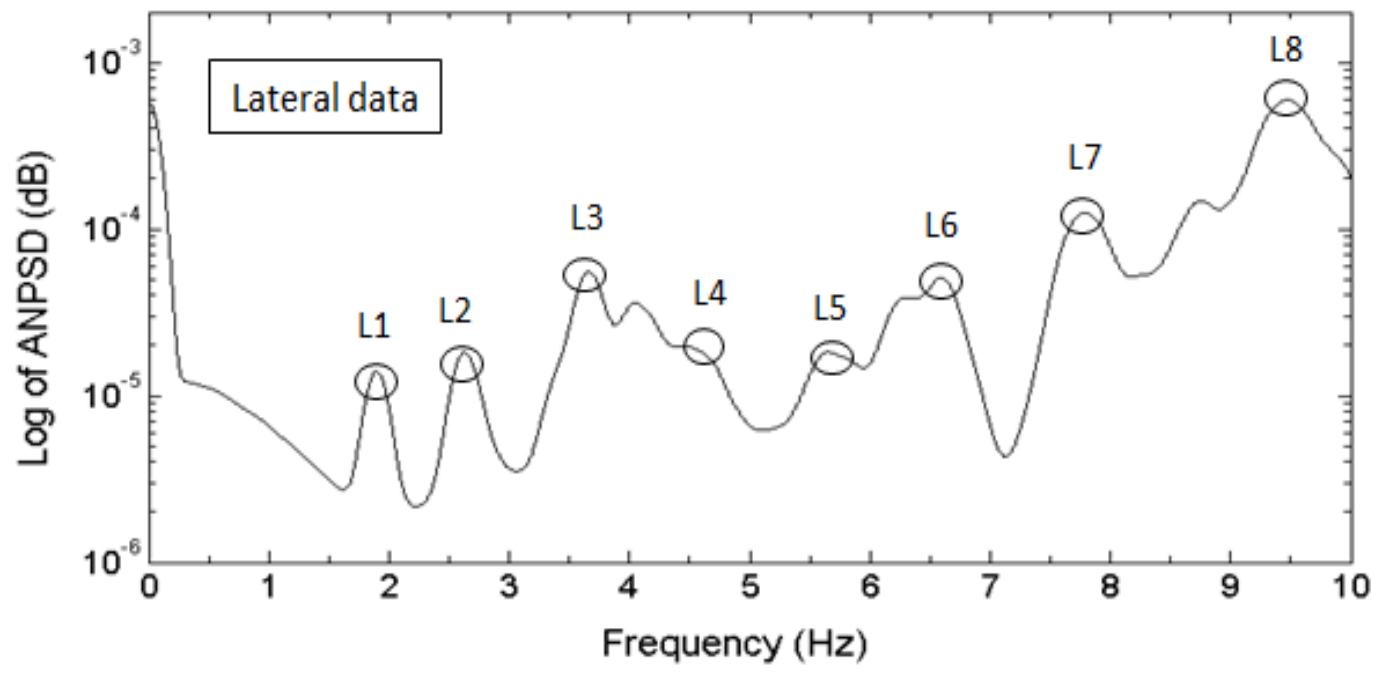

Figure 9. Averaged normalized power spectral densities: a) vertical response, and b) lateral response.

Chen et al. 


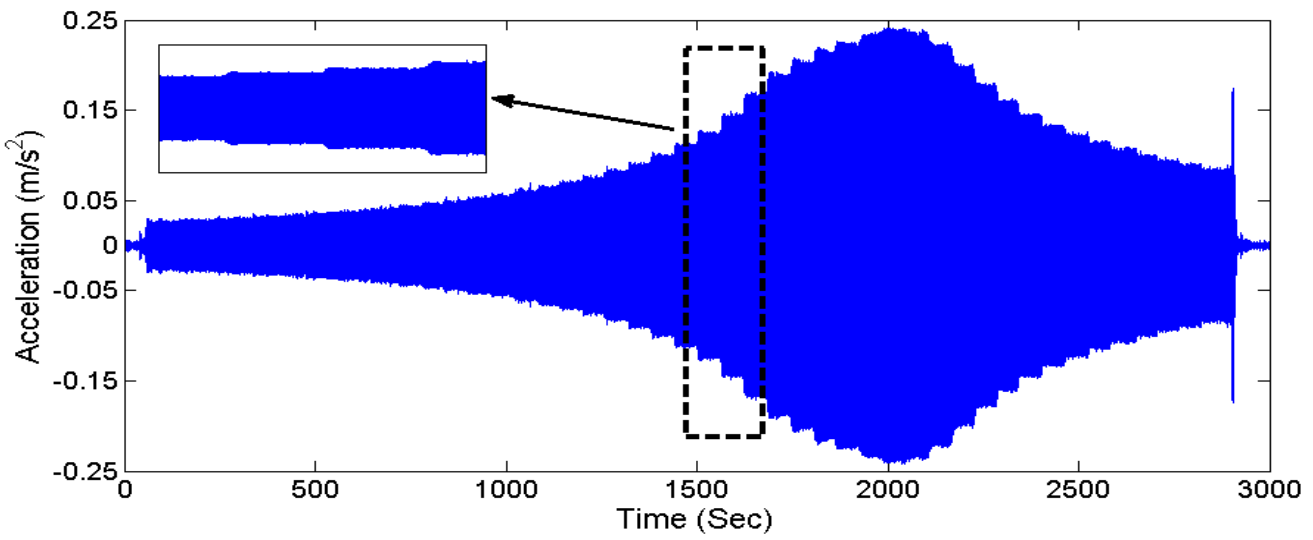

Figure 10. Response due to detailed sweeping test around mode V1.

Chen et al. 

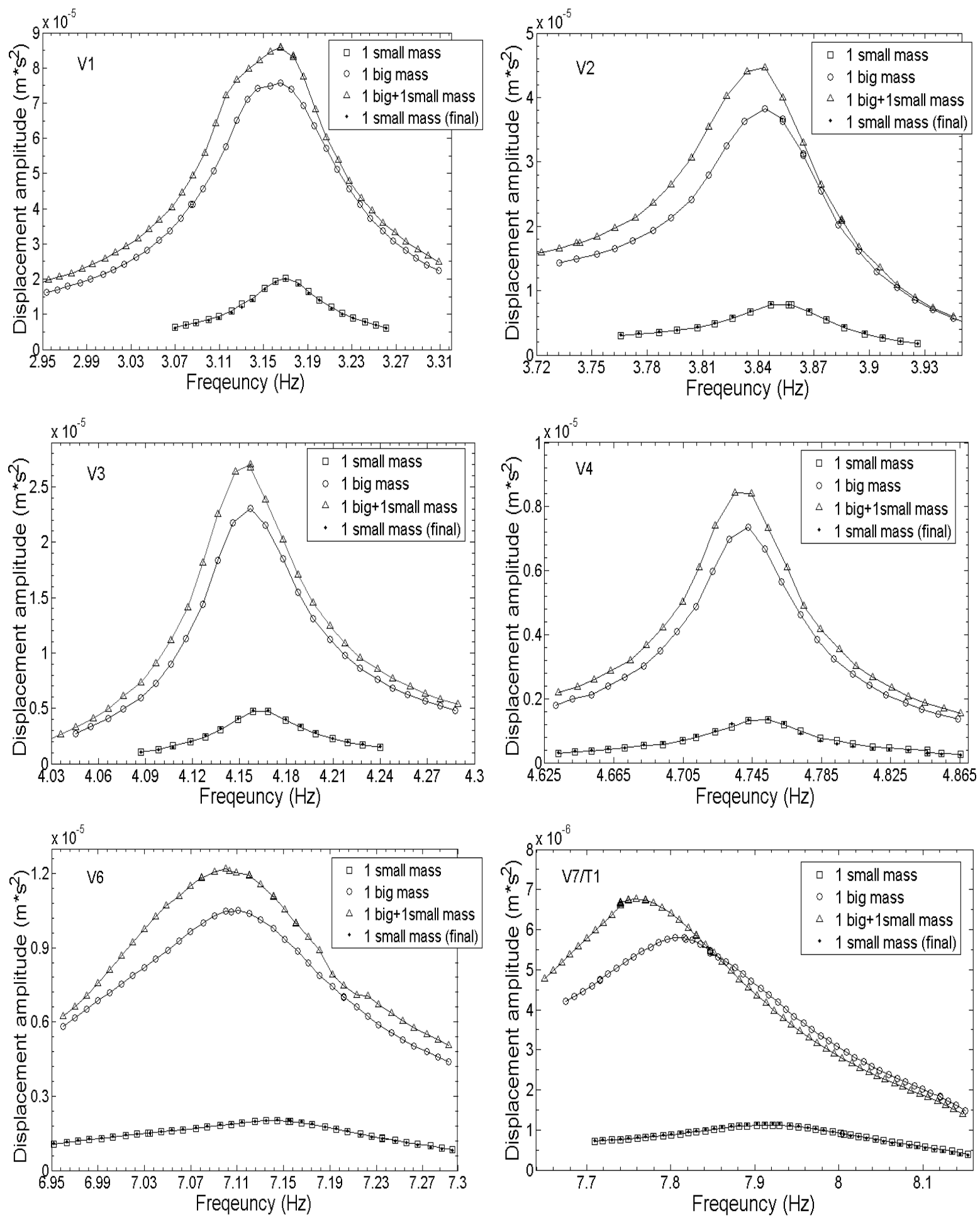

Figure 11. Displacement amplitudes as functions of frequency for vertical and verticaltorsional modes.

Chen et al. 

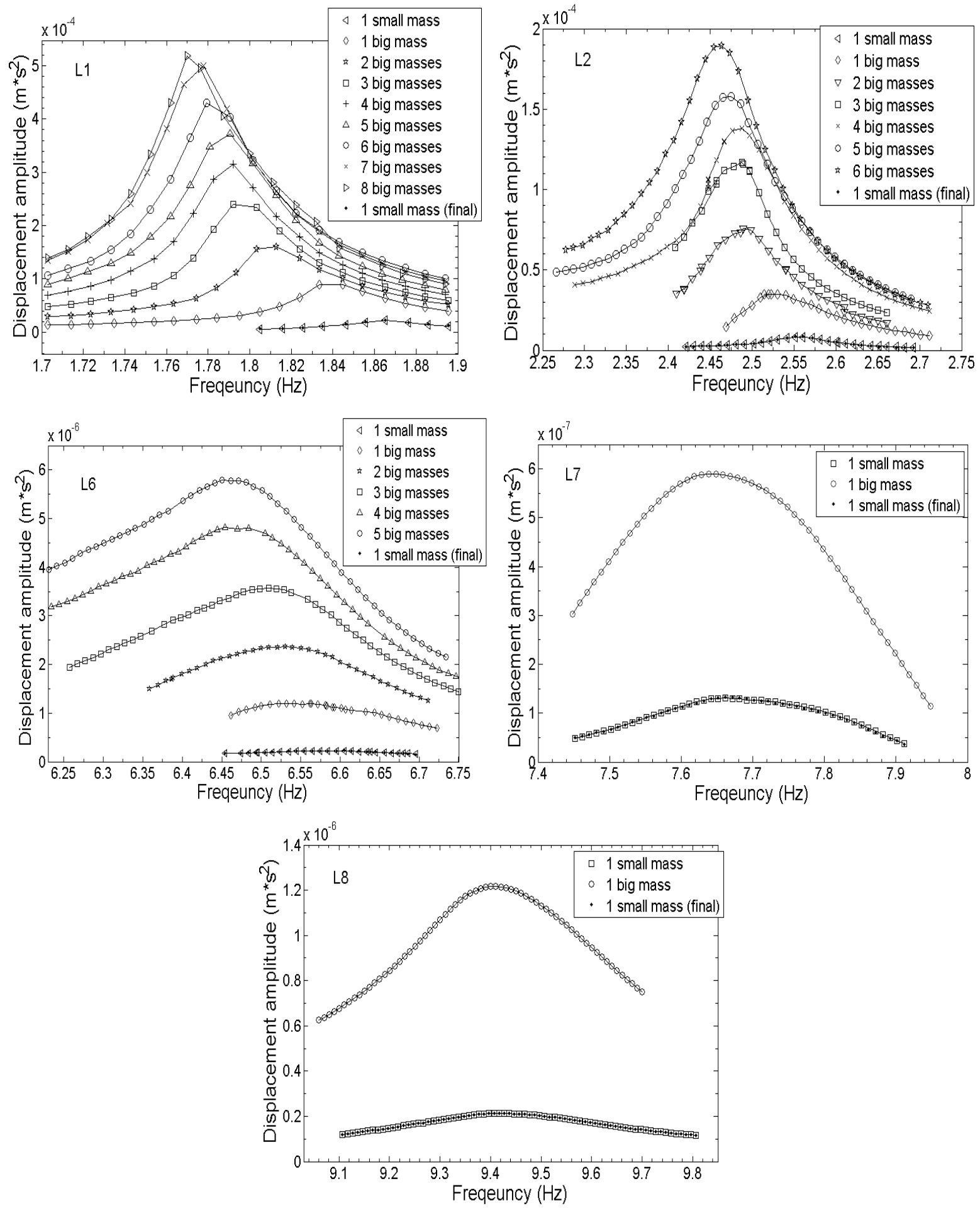

Figure 12. Displacement amplitudes as functions of frequency for lateral modes.

Chen et al. 

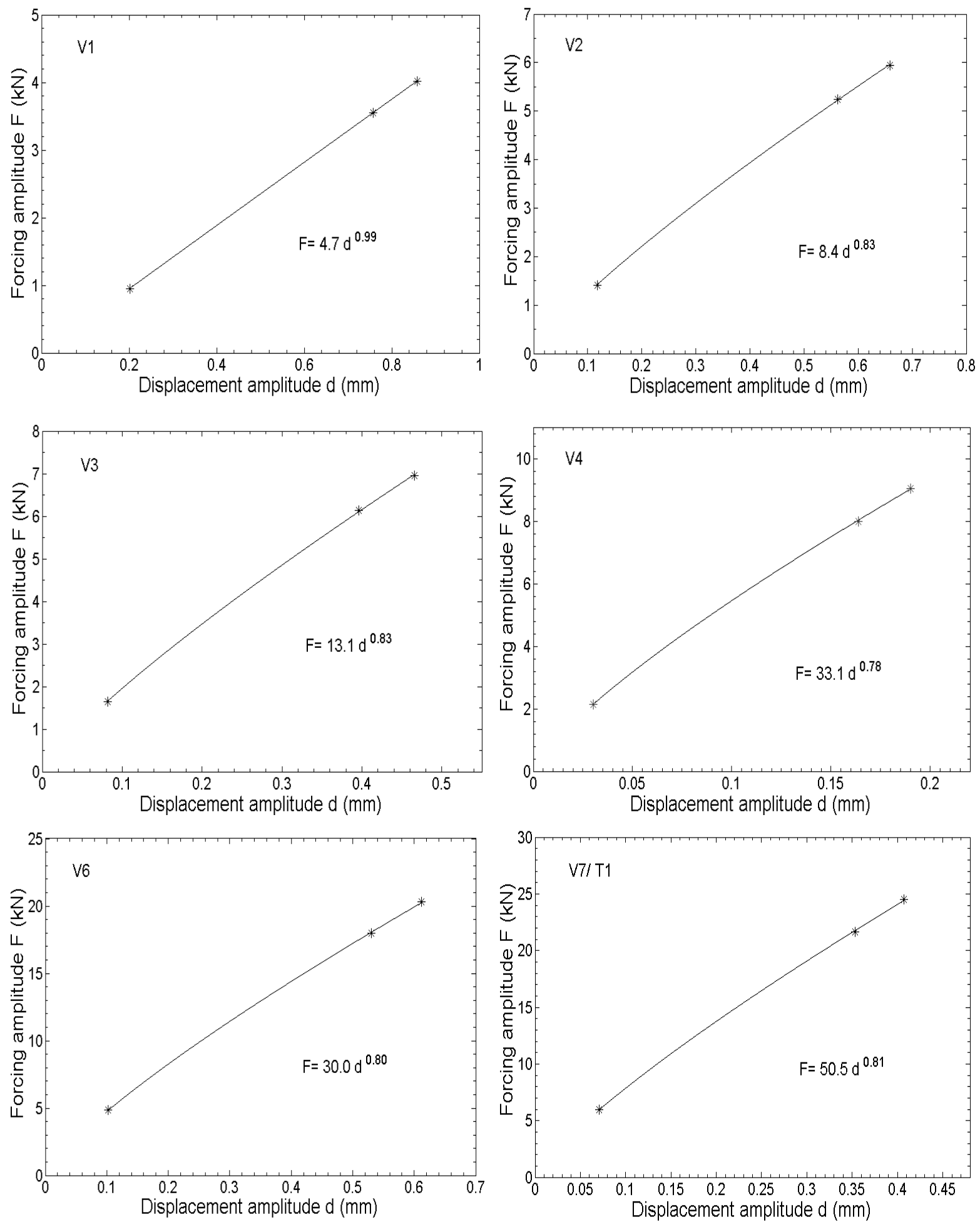

Figure 13. Displacement amplitude vs. forcing amplitude for vertical and vertical-torsional modes.

Chen et al. 

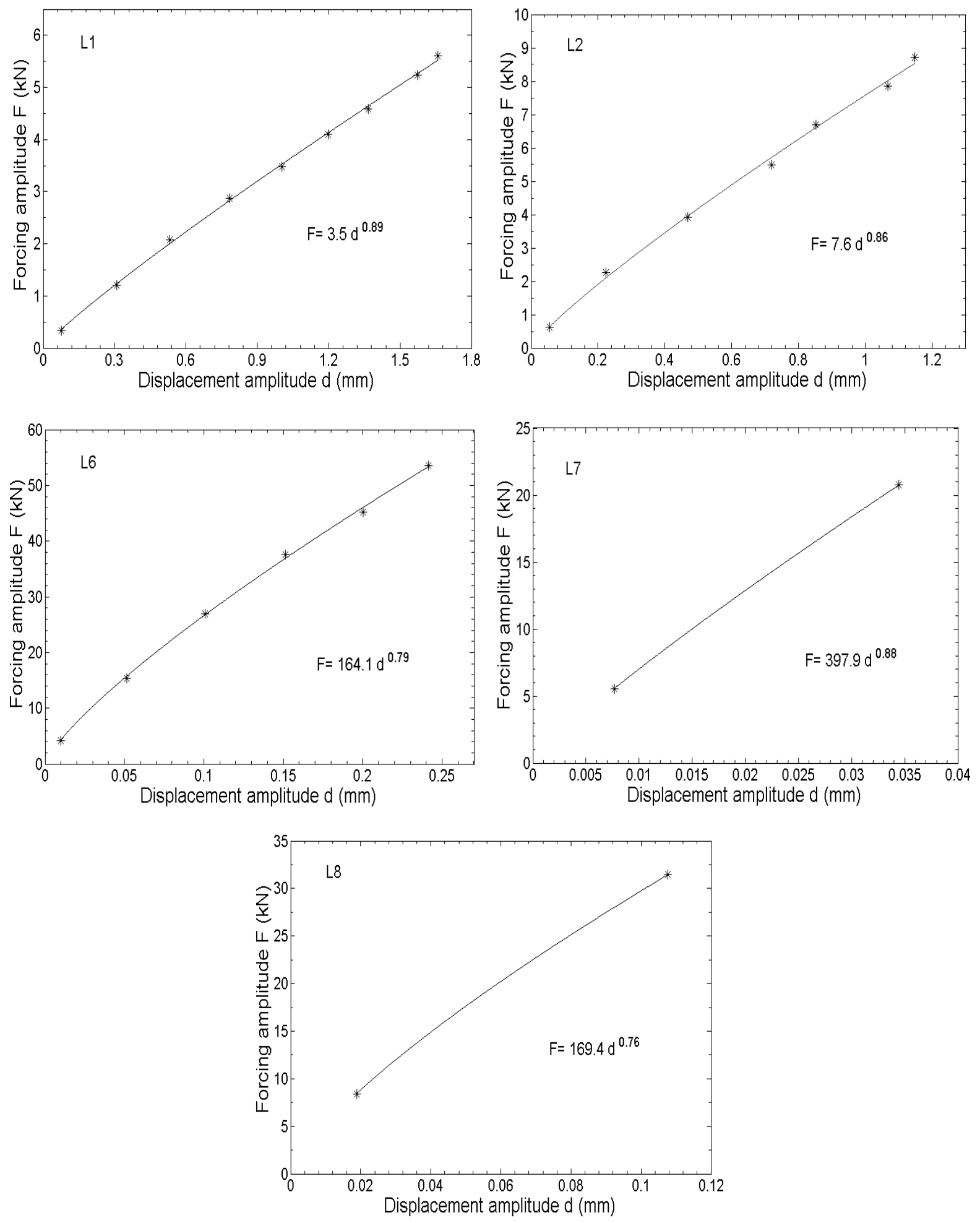

Figure 14. Displacement amplitude vs. forcing amplitude for lateral modes.

Chen et al. 

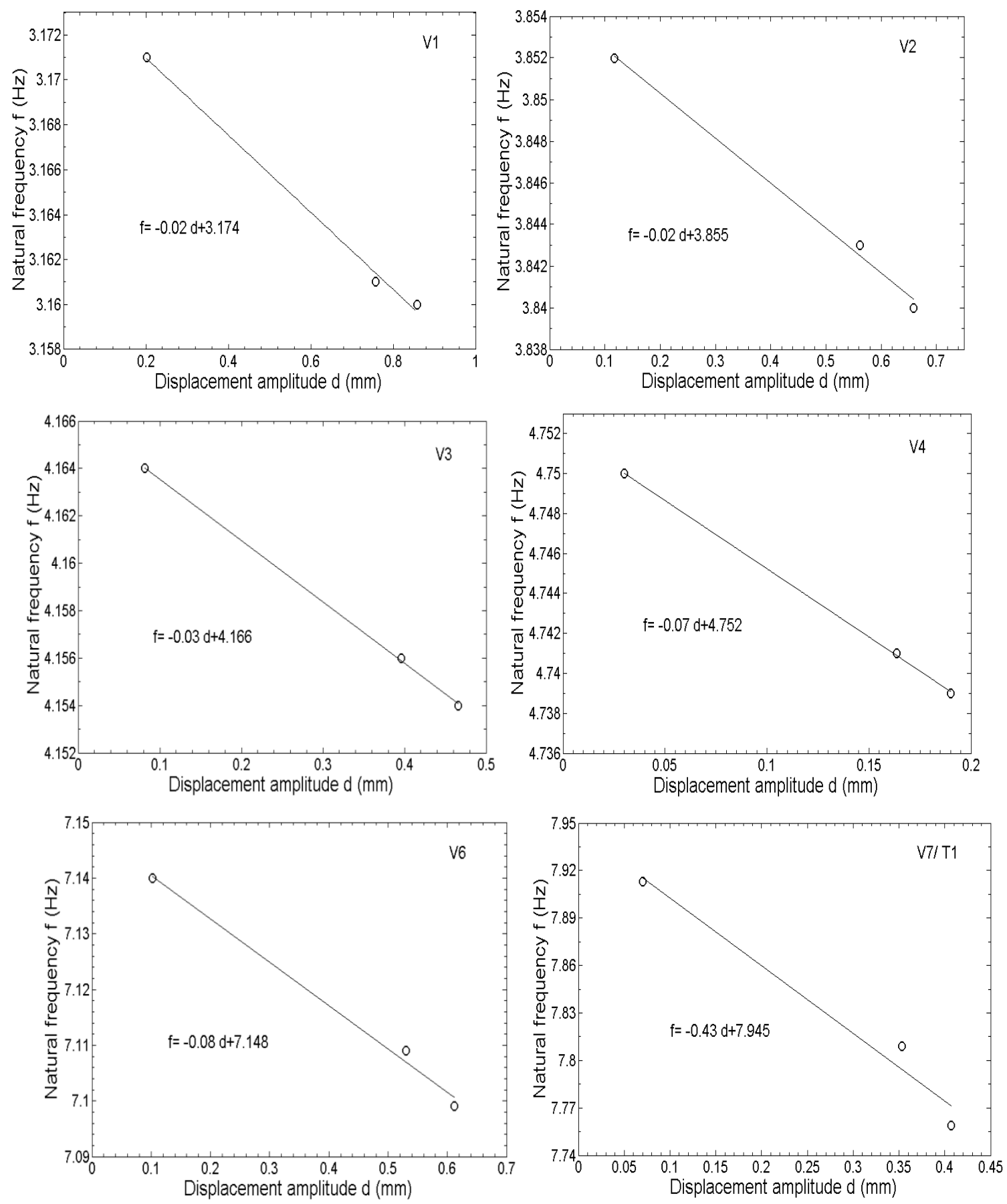

Figure 15. Modal frequencies vs. displacement amplitudes for vertical and vertical-torsional modes.

Chen et al. 

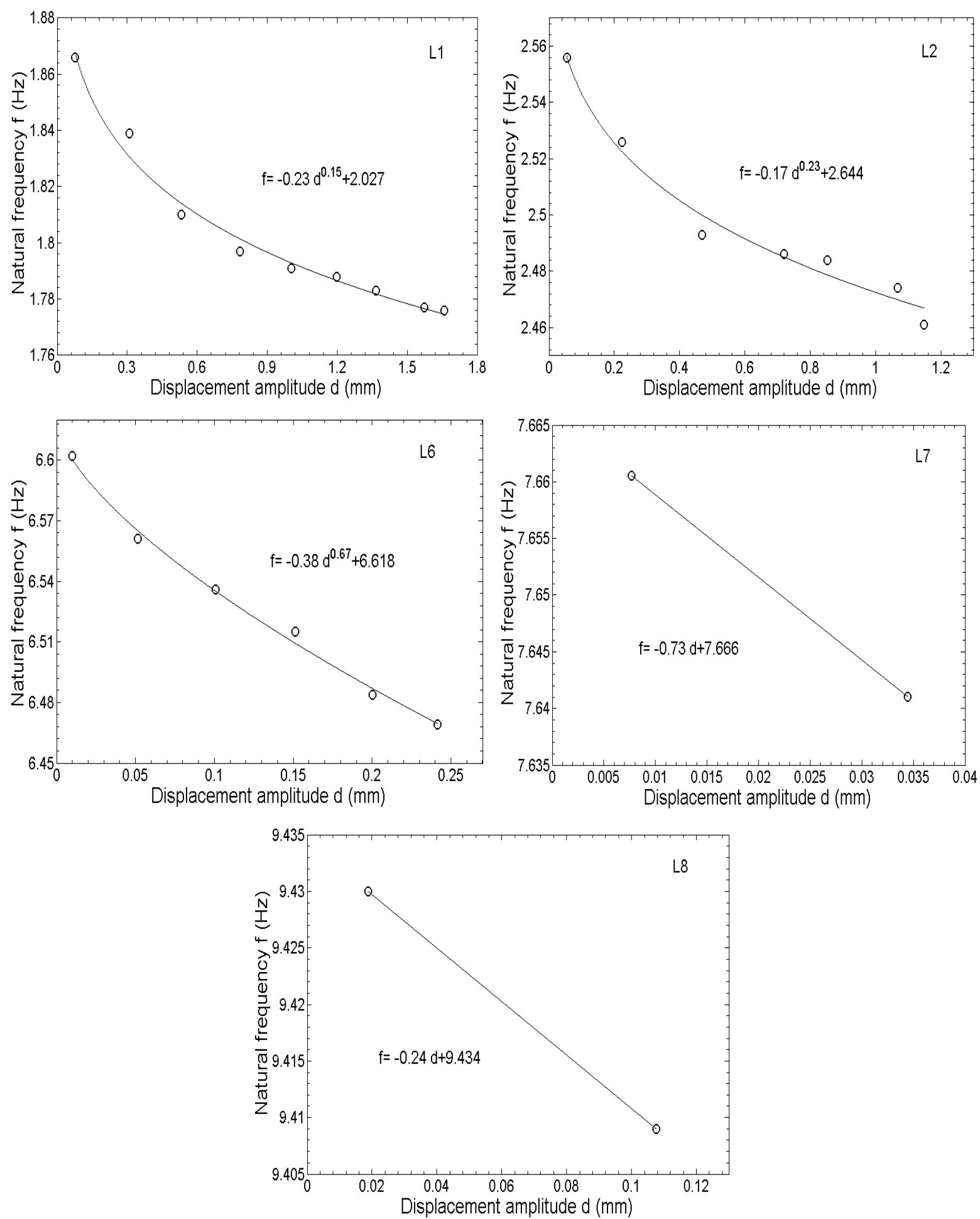

Figure 16. Modal frequencies vs. displacement amplitudes for lateral modes.

Chen et al. 

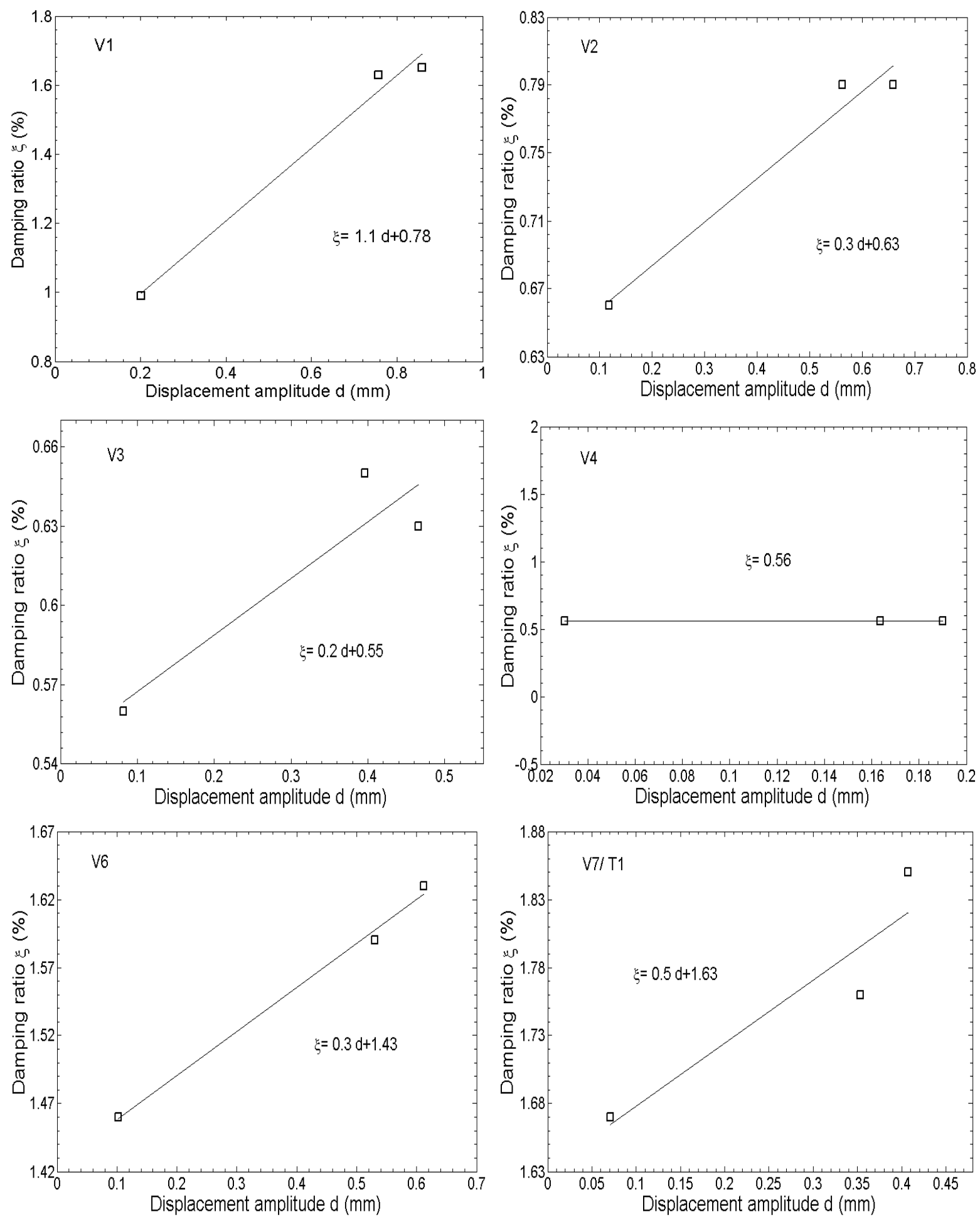

Figure 17. Damping ratios vs. displacement amplitudes for vertical and vertical-torsional modes.

Chen et al. 

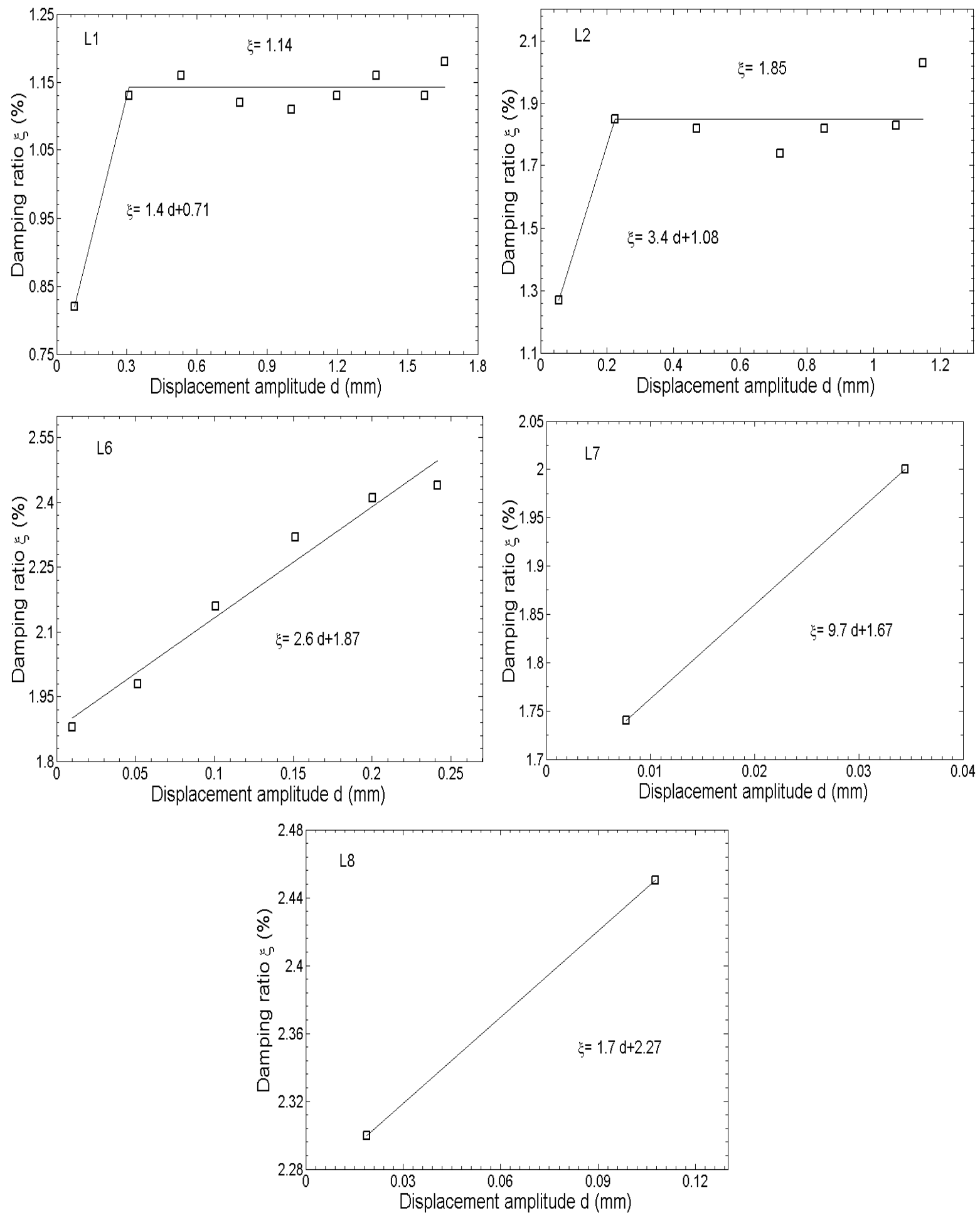

Figure 18. Damping ratios vs. displacement amplitudes for lateral modes.

Chen et al 


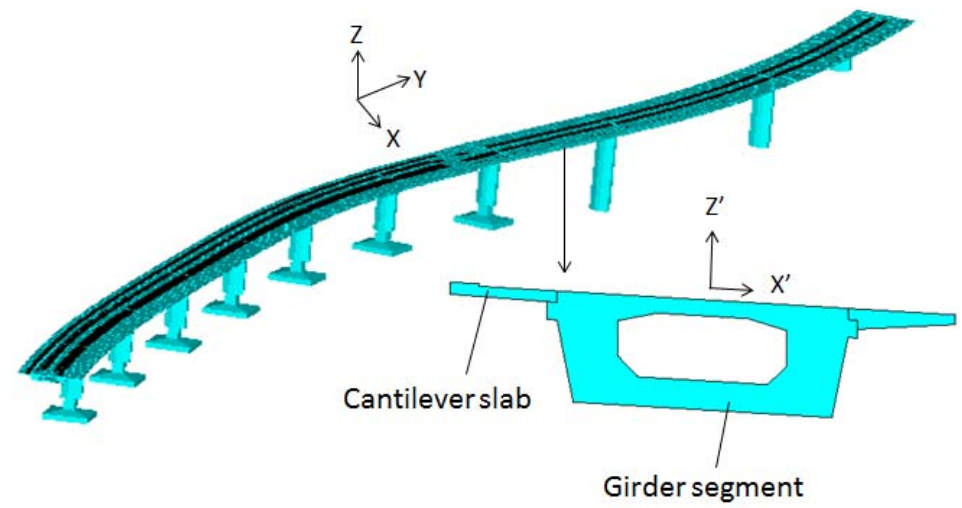

Figure 19. Numerical model of the bridge.

Chen et al. 


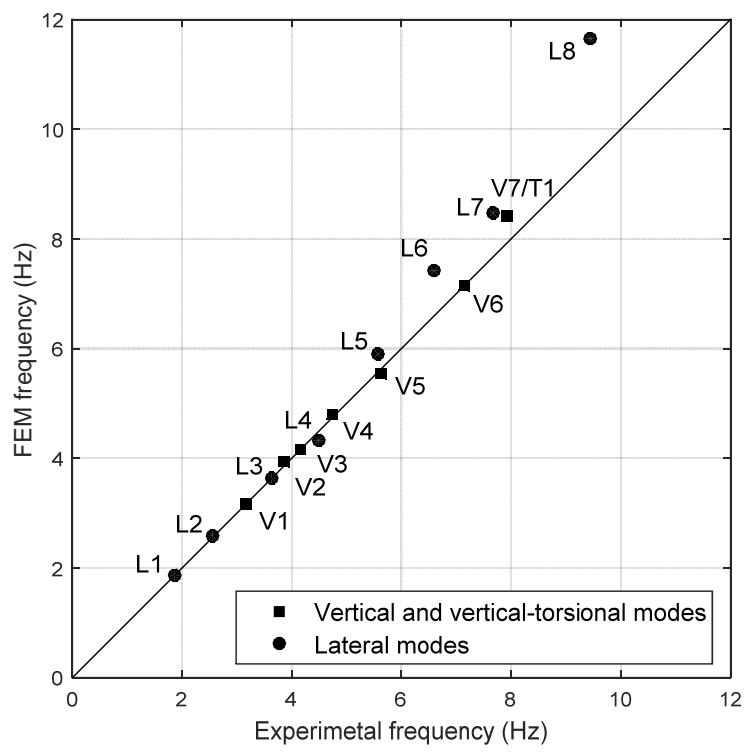

Figure 20. Graphical comparison of experimental and numerical frequencies.

Chen et al. 

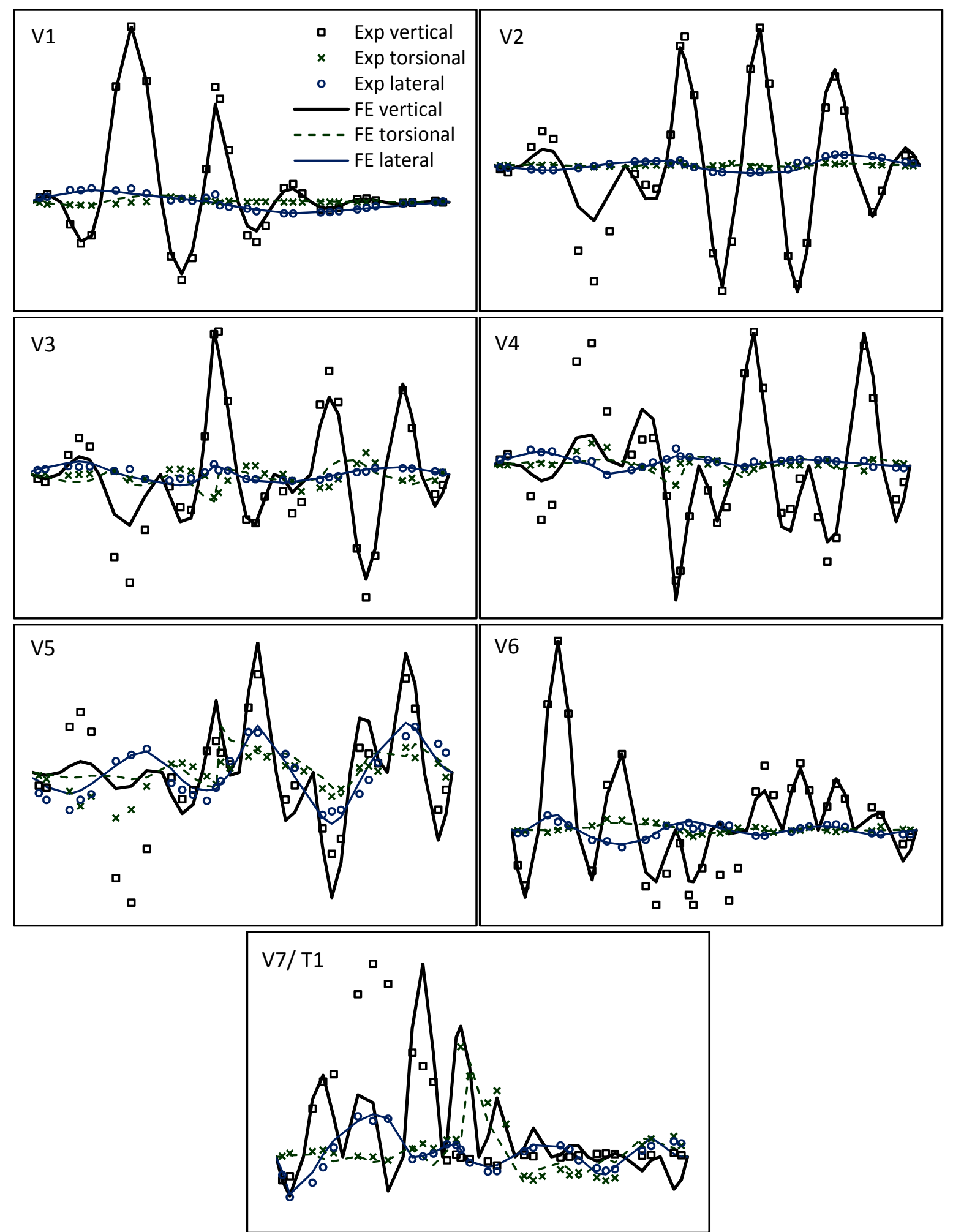

Figure 21. Experimental and FE model vertical and vertical-torsional mode shapes.

Chen et al. 

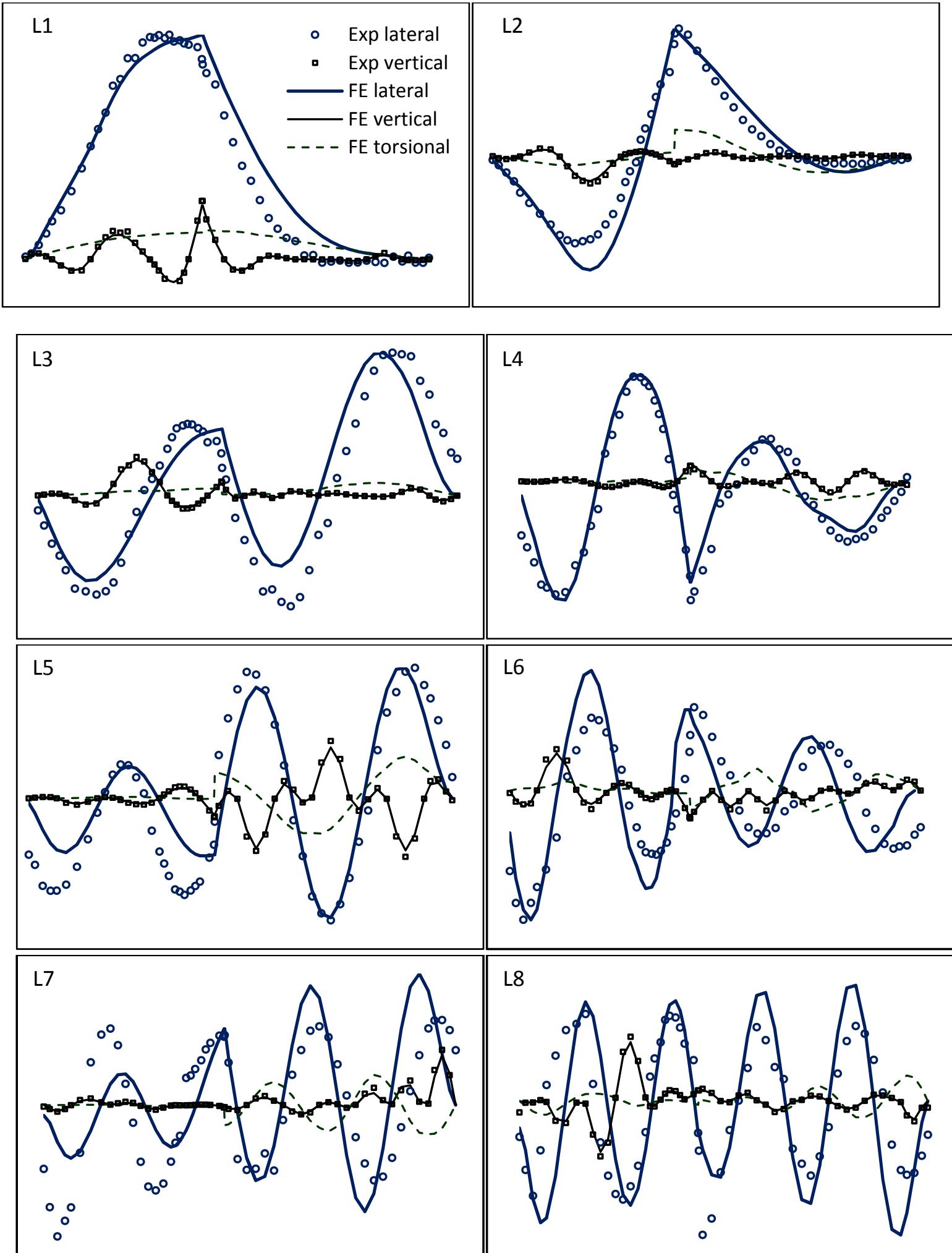

Figure 22. Experimental and FE model lateral mode shapes.

Chen et al. 


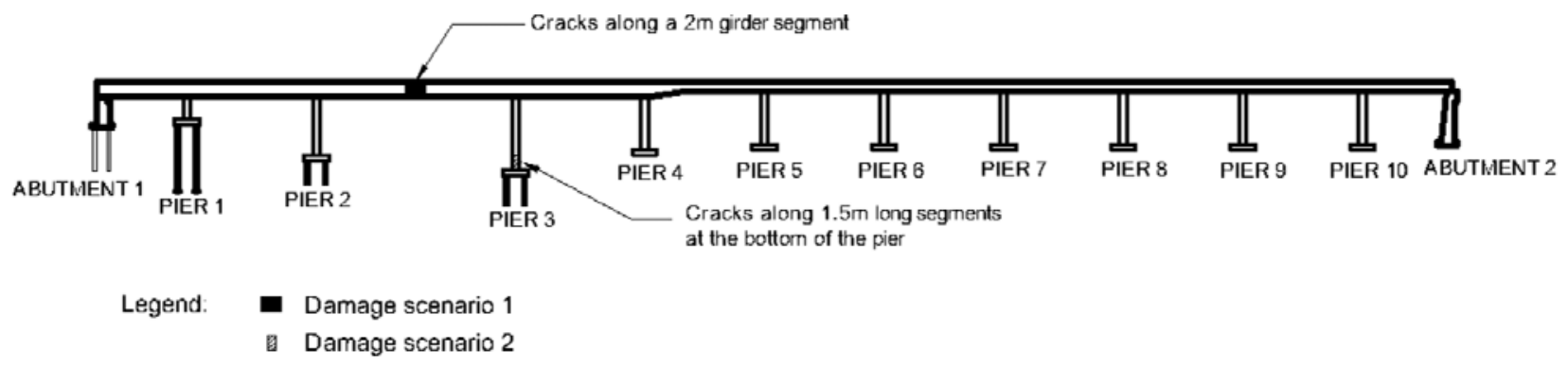

Figure 23. Numerical damage scenarios.

Chen et al. 